\title{
Operations Research for Managers of Reproductive Health
} Programs

\author{
James R. Foreit \\ Population Council \\ M.E. Khan \\ Population Council
}

Follow this and additional works at: https://knowledgecommons.popcouncil.org/departments_sbsr-rh

Part of the Demography, Population, and Ecology Commons, Family, Life Course, and Society Commons, Health Services Research Commons, International Public Health Commons, and the Medicine and Health Commons

How does access to this work benefit you? Let us know!

\section{Recommended Citation}

Foreit, James R. and M.E. Khan. 2008. "Operations Research for Managers of Reproductive Health Programs." Washington, DC: Population Council. 


\section{Operations Research for Managers of Reproductive Health Programs Course Introduction}

This course defines operations research (OR) as the study of factors under the control of health program managers and other decision-makers. The purpose of OR is to improve programs and provide information for management decision-making. Successful OR is characterized by a close collaboration between program managers and researchers throughout the study. This collaboration requires that managers have some understanding of research and that researchers have some understanding of health programs. The course does not cover operational analysis - the branch of applied mathematics that includes decision analysis, linear programming, queuing models, etc. Rather the focus is on OR as a branch of the behavioral sciences and deals with formative research and field experiments. The examples and exercises in this course are largely based on operations research studies in reproductive health projects in developing countries.

Lack of research knowledge among program decision-makers is a major barrier to utilization of research findings and adoption of best practices. Researchers in the field of utilization are almost unanimous in identifying research training as key to utilization of research results. Training results in greater confidence by managers and providers to act on research results, and influences information seeking behavior. Managers with research training are far more likely to seek information on research findings and evidence based best practices than are those without research training ${ }^{1,2,3,4,5,6,7}$.

This course concentrates on improving the research knowledge of managers who have had little or no training in research. Its focus is on improving the quality of the managerresearcher interaction and, hopefully, it will increase the use of OR as a program improvement tool. Specifically, the course familiarizes health program managers and decision-makers with the principles and vocabulary of operations research, especially intervention projects; and equips the manager to play an active and effective role in field experiments and other types of program research. More generally, the course aims to stimulate managers to seek out research data in making program decisions, even when an operations research project is not being contemplated.

Because managers have limited time available for training, the course is intended to be completed in four days. Given the large amount of material that must be absorbed, we recommend avoiding potential information overload by limiting course time to six hours daily. The course is intended to be highly interactive and consists of presentations, exercises, and discussion of handouts. Although the course is aimed at professionals with little or no research background, it is essential that facilitators have a background in applied health research, especially in field experiments and intervention programs.

The course is based on the experience of many researchers, especially those who have participated in the United States Agency for International Development funded Frontiers in Reproductive Health Program (FRONTIERS). The course has been conducted in Africa, Asia, the Middle East, former Soviet Block countries, and the United states. This version is based on the most successful materials from those courses. Because of its interactive nature, it is recommended that the course be limited to approximately 20 participants. Facilitators are invited to use the course materials so long as credit is given 
to the Population Council FRONTIERS program. Facilitators are also encouraged to modify the course to increase its relevance to different types of programs.

Topics covered in the course and the approximate time that should be devoted to each are shown in the table below.

Table: Course sessions and duration

\begin{tabular}{|l|l|}
\hline Session & Approximate Duration \\
\hline 1. What is OR? & 1 hour \\
\hline 2. Exercises: What is OR? & $1 \frac{1 / 2}{\text { hours }}$ \\
\hline 3. Managers Role in OR & 1 hour \\
\hline 4. Exercises: Managers Role in OR & 2 hours \\
\hline 5. Identifying Problems and Solutions & 1 hour \\
\hline 6. Exercises: Identifying Problems and Solutions & 1 hour \\
\hline 7. Causality & $1 \frac{1}{2}$ hours \\
\hline 8. Quasi- and Non-experimental Designs & $1 \frac{1 / 2}{\text { hours }}$ \\
\hline 9. Exercises: Designs & 2 hours \\
\hline 10. Conducting a Study & 1 hour \\
\hline 11. Exercises: Conducting a Study & 1 hour \\
\hline 12. Dissemination & 1 hour \\
\hline 13. Research Ethics & 1 hour \\
\hline 14. Exercises: Research Ethics & $11 / 2$ hours \\
\hline 15 The Research Budget & 1 hour \\
\hline 16. The Research Proposal & 1 hour \\
\hline 17. Exercises Research Proposal Critique & $2 \frac{1}{2}$ hours \\
\hline 18. Wrap-up and Question and Answer Session & 1 hour \\
\hline & $23 \frac{1}{2}$ hours \\
\hline Duration & \\
\hline
\end{tabular}

Hard copies of course presentations, exercises, handouts, and CD should be provided to participants for use during the course. However, the instructor's guides and exercise solutions should not be provided to participants. The course does not require the use of computers.

Two books are recommended as references for course facilitators including: Andrew $A$. Fisher and James R. Foreit (200), Designing HIV/AIDS Intervention Studies, an Operations Research Handbook, The Population Council, NY; and any one of the many editions of Donald T. Campbell and Julian C. Stanley, Experimental and QuasiExperimental Designs for Research. The former work is included as part of the materials accompanying this course, and is also available on the Population Council Website, www.popcouncil.org

Authored by:

James R. Foreit (first author)

Senior Associate

Population Council
Mohammed E. Khan (second author) Senior Associate Population Council 


\section{References}

1. Egerod, I. and G.M. Hansen. 2005. "Evidence-based practice among Danish cardiac nurses: A national survey," Journal of Advanced Nursing, 51(5): 465-473.

2.

Gerrish, K. and J. Clayton. 2004. "Promoting evidence-based best practice: an organizational approach," Journal of Nursing Management, 12: 114-123.

3. Glacken, M. and D. Chaney. 2004. "Perceived barriers and facilitators to implementing research findings in the Irish practice setting," Journal of Clinical Nursing, 13: 731-740.

4. Hutchinson, A. M. and L. Johnston. 2004. "Bridging the divide: A survey of nurses' opinions regarding barriers to, and facilitators of, research utilization in the practice setting," Journal of Clinical Nursing, 13: 304-315.

5. Kosteniuk, J.G. et al. 2006. "Central and peripheral information source use among rural and remote Registered nurses," Journal of Advanced Nursing, 55(1): 100-114.

6. Ring, N. et al. 2006. "Analysis of the impact of a national initiative to promote evidence- based nursing practice," International Journal of Nursing Practice, 12: 232-240.

7. Veeramah, V. 2004. "Utilization of research findings by graduate nurses and midwives," Journal of Advanced Nursing, 47(2): 183-191. 


\section{Session 1: Instructor's Guide What is Reproductive Health Operations Research?}

\section{SESSION OBJECTIVES:}

- To provide participants with a definition of operations research

- To expand on the basic definition of OR with examples of each element of the definition

\section{POINTS TO EMPHASIZE:}

- OR is distinguished from other types of research by its focus on factors under the control of managers - it is neither superior nor inferior to other types of research that are relevant to programs, but it is different.

- Successful OR requires close collaboration between researchers and managers.

- OR results should be immediately applicable to program problems.

- Define independent and dependent variables. They can also be referred to as interventions and outcomes. Understanding the terms is basic to understanding the course.

\section{SESSION METHOD}

- Presentation and discussion

- The presentation order begins with an expanded definition of OR. The elements of the definition are the titles of subsequent slides. Each title is illustrated by examples on the same slide. For example, slide 6 is titled "Program Objectives." The title is then followed by a list of program objectives with a definition of each objective.

\section{EXERCISES:}

- Session one contains a single exercise (slide 9). The purpose of the exercise is to have participants identify the essential elements of an OR study. The instructor should read the problem and then ask the class to identify the dependent variable (output, outcome, impact) that they would like the OR project to improve. Finally, participants should identify the factors under managerial control that can be manipulated to improve the program result.

DURATION: 1 hour

\section{Materials}

1. PowerPoint presentation "What is Reproductive Health Operations Research" 


\section{What Is Reproductive Health Operations Research?}

\section{FRONTIERS in Reproductive Health Program 2008}




\section{Operations Research (OR) is the study of factors under the control of program managers.}

\section{OR uses research techniques to help choose among alternative uses of resources to meet specified program objectives.}




\section{Research Focus}

Factors controlled by managers

Outcomes desired by managers and clients

\section{Independent variables: manipulated by managers Dependent variables: program outcomes}




\section{OR Supports Evidence- Based Programs}

- Supports decisions with empirical evidence

- Arrives at "best practices" by comparison

- Tests service delivery innovations 


\section{Programs are the Substance of OR}

Health programs are organized activities that seek to promote the health and well-being of communities or populations. 


\section{Program Objectives}

- Access: Availability of services geographically, economically, administratively

- Efficiency: Maximization of outcomes at a given resource level

- Quality: Appropriateness and competency of services

- Impact: Improvements in health 


\section{Programs Produce}

- Outputs: Program services

- Outcomes: Client behaviors

- Impacts: Improvements in health status 


\section{Managerial Control}

\section{Factors Under Control}

Program systems: training, pricing, information, counseling ...

\section{Factors Not Under Control}

Cultural beliefs, location, economic status, religion, education... 


\section{OR Access Problem}

- Program Problem: How to get more adolescents to use reproductive health clinic

- Managerial Factors: Price, hours, provider training...

- Output: More visits to clinic by adolescents

- Outcome: More contraceptive use

- Impact: Fewer unwanted pregnancies 


\section{Achieve a Specified Outcome}

The outcome must be determined in advance:

- Lower cost per service

- Reduction in C-sections

- Decreased HIV incidence

- Increased postnatal visits 


\section{Research Techniques}

- Systematic data collection

- Diagnostic/formative studies to identify problems

- Experiments, simulations to choose between alternatives 


\section{Diagnostic/Formative Research}

- Descriptive studies

- Done when reason for program problem is unknown or to determine if problem exists

- Suggests possible solutions 


\section{Intervention Research}

- Experiments

- Factors under manager's control

- Tests solutions to program problems

- Compares alternatives 


\section{Evaluation}

- Usually descriptive and retrospective

- Deals with factors under and not under managers' control

- Focus on attainment of project objectives

- Can use experiments

- Line between OR and evaluation often blurred 


\section{OR: Applied to all Service Delivery Modalities}

- Hospitals

- Clinics

- Community Programs

- Public Programs

- NGO Programs

- For-profit Providers 


\section{OR Requires Collaboration}

- Managers:

responsible for decision parameters and desired outcome

- Researchers:

responsible for recommending and implementing research techniques 


\section{OR is Not Methodologically Defined}

\section{Different methods used in OR studies:}

- Quantitative

- Qualitative

- Surveys

- Experiments

- Focus Groups

- Simulations 


\section{Decision Determines Method}

- What information is needed to make decision?

- When must the decision be made?

- How much can we spend?

- What precision is needed in data (consequences of wrong decision) 


\section{Steps in the OR Process}

1. Identify the problem

2. Generate solutions

3. Test intervention to solve the problem

4. Ensure results are used

5. Disseminate results 


\section{OR is successful only if the results are used to make program decisions}

\section{Published papers are not valid indicators of OR success}




\section{Session 2: Instructor's Guide Exercises: Key OR Concepts}

\section{SESSION OBJECTIVES:}

- To strengthen the knowledge of key OR concepts introduced in session one.

\section{POINTS TO EMPHASIZE:}

- Three concepts are reinforced by this exercise including:

1. The difference between outputs, outcomes, and impacts (exercises 1 and 2)

2. Independent (interventions) and dependent variables (outputs, outcomes, or impacts) Exercises 3-4.

3. The differences between OR and other types of research (exercise 5)

The facilitator should emphasize that the difference between types of research is often not clear cut in practice.

\section{SESSION METHOD:}

- Exercises 1-4 should be done in a large group. The facilitator should begin by calling volunteers and/or specific individuals. Participants should be asked to provide other examples of outputs, etc. Exercise 5 (handout) should be done in small groups. Each group should be asked to discuss why or why not the three examples are OR. The first example is interventions operations research, the second is not operations research, and the third is an evaluation. Debate between groups should be encouraged.

DURATION: $1 \frac{1}{2}$ hours

\section{Materials}

1. PowerPoint Presentation "Exercises Key OR Concepts"

2. Handout "Exercise 1: What type of study?" 


\section{Key OR Concepts}

\section{Exercises}




\section{Exercise 1:}

\section{Output? Outcome? Impact?}

- Change in HIV incidence

- Number of women attending health meeting

- Number of brochures distributed

- Percent of children sleeping under bednets

- Number of students signing abstinence pledge

- Number of students practicing abstinence

(P) Population Council FRONTIERS 


\section{Exercise 2: \\ Give Outputs, Outcomes, and Impacts}

- 3 outputs for a family planning program

- 2 impacts of a Tuberculosis program

- 3 outcomes of an HIV program

- 2 outputs of a malaria control program

- 1 impact of an HIV program

- 2 impacts of a family planning program 


\section{Exercise 3: Design an OR Study}

- Program Problem: Low acceptance of treated bed nets

- State Factors to manipulate (Intervention)

- Identify improved acceptance measures, including an output, outcome, and impact:

- 1 output

- 1 outcome

-1 impact

(2) Population Council FRONTIERS

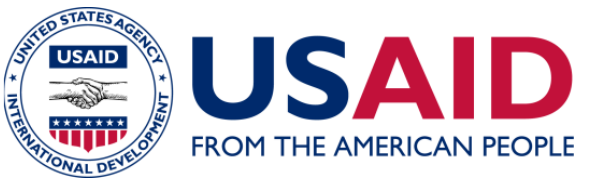




\section{Exercise 4: \\ Design an OR study}

- Problem: TB program providers are not following the DOTS protocol correctly

- State factors to manipulate (intervention)

- Identify improved performance measures at the output, outcome, and impact levels 


\section{Exercise 5: \\ What Type of Study?}

- Read each of the abstracts. For each abstract decide

- Is the study OR? Why or why not?

- Is the study an intervention? Diagnostic? Neither? 


\section{Session 2: Exercise 1 What type of study?}

Thinking about the characteristics of an operations research project, read each of the brief abstracts below. For each abstract tell us if the study is operations research, and why it is or is not. If the study is operations research, tell us if it is an intervention or a diagnostic study.

\section{Studying the effectiveness of different approaches to malaria treatment regimen adherence.}

A malaria program in Uganda tested supervised versus unsupervised use of artemetherlumefantrine (A-L) . The six-dose regimen of $A-L$ has been prioritized to replace nolonger effective antimalarial treatments in Africa. Since the new therapy requires a relatively complicated three day course of treatment, there was concern that effectiveness of the new treatment could be compromised by poor adherence, which could also result in producing strains of malaria resistant to A-L. It was thought that supervised therapy could increase adherence. Although potentially maximizing the effectiveness of treatment, supervised therapy would be expensive for the program and complicated for patients, and could seriously limit utilization of the drug.

A randomized controlled trial comparing treatment outcomes of malaria patients receiving supervised and unsupervised treatment was conducted in the Mbarara University Teaching Hospital in Uganda. After first giving informed consent, 957 malaria patients were randomly assigned to either supervised or unsupervised treatment groups. Supervised treatment consisted of admitting patients to an in-patient clinic for three days and closely supervising the course of treatment. The unsupervised treatment group was given careful counseling on how to use the drug and was allowed to take the drug at home. Twenty-eight day cure rates were $97.7 \%$ for the supervised group, and $98.0 \%$ for the unsupervised group, indicating that an A-L program could be based on unsupervised treatment.

\section{The reproductive health of women perinatally infected with HIV}

A study in the United States was done to describe the reproductive health of adolescent girls perinatally infected with HIV. It estimated the incidence of first pregnancy, genital infections and abnormal cervical cytology for 638 girls aged 13 years and older. Thirtyeight girls became pregnant. Thirty-two pregnancies resulted in live births. All girls received antiretroviral therapy during pregnancy. One infant was HIV infected, 29 were uninfected, and 2 had unknown infection status, for a rate of mother-to-child transmission of HIV of $3.3 \%$. Condylomata and trichomoniasis were the most frequent genital infections. Forty-eight (47.5\%) of 101 girls with Papanicolaou examinations had abnormal cervical cytology, including atypical cells of undetermined significance $(n=18)$, low-grade squamous intraepithelial lesions (SIL; $n=27)$, and high-grade SIL $(n=3)$. Many abnormalities persisted despite intervention. Pregnancy rates were lower and cervical abnormalities were higher than among non-HIV-infected adolescents. These findings underscore the importance of Papanicolaou tests and promotion of safer sexual practices in this population. 


\section{Female condom use in Zimbabwe}

One year after the start of a female condom social marketing campaign, a study was conducted of users of the product. The goal of the study was to increase understanding of the dynamics of female condom use to inform program planners. The study used a combination of quantitative and qualitative methods. Users were in their mid-twenties. About $15 \%$ of women reported always using the female condom. Consistent use was reported less frequently with spouses than partners outside of marriage. STI/HIV protection increased among some users. Twenty-seven percent had never used a male condom, and $20 \%$ of all consistent users reported not being consistent male condom users prior to trying the female condom. Results of the study indicate that one year after the start of the social marketing campaign, the female condom was being used in regular partnerships, thus reflecting the aims of the campaign. 


\section{Session 3: Instructor's Guide Manager's Role in Operations Research}

\section{SESSION OBJECTIVES:}

- To introduce the role of the manager and researcher in the operations research collaboration

\section{POINTS TO EMPHASIZE:}

- The manager's role in OR is at least as, if not more important than, the role of the researcher

- The manager identifies the program problem to be researched, sets the research parameters, and is responsible for utilization of results

- What the manager should do when contracting research

- The researcher is responsible for the integrity of the study

- Collaboration between managers and researchers is essential during all phases of the study

\section{SESSION METHOD:}

- Presentation and discussion

- The slides begin with a list of broad areas within the manager's role. Subsequent slides explain the broad areas in detail

\section{EXERCISES:}

DURATION: 1 hour

\section{Materials}

1. PowerPoint Presentation: "Manager's Role in Operations Research" 


\section{Manager's Role in Operations Research}




\section{Manager's Role in Operations Research}

- Identify program problem or decision

- Decide if research required

- Set limits on research (time, resources)

- Ensure that providers/managers collaborate

- Plan for utilization and scaling-up

- Plan for dissemination 


\section{Is Research Needed?}

- Research should be avoided if possible

- Look at existing data sources

- Conduct research if problem cannot be solved by common sense, experience

- If research needed: Decide formative/diagnostic or intervention? 


\section{Choosing Solutions for Testing}

- Sources of solutions: Program staff, clients, community, literature, researchers

- Evaluating Solutions:

- Affordable and sustainable?

- Easy to implement?

- Evidence the solution can be successful?

- Can results be measured? 


\section{Setting Boundaries on the Research Design}

- Identify information needed for decision

- Determine when the information is needed (set research time frame)

- Determine precision required from the data (what is the consequence of a bad decision?)

- Decide tolerable level of program disruption

- Identify/provide resources for study

(P) Population Council FRONTIERS 


\section{Manager's Role in Monitoring Research}

- Make sure staff cooperate with research effort

- Maintain contact with researchers throughout study

- Check with researchers before making program changes that might affect research effort 


\section{Manager's Role in Utilization of Research Results}

- Know what you will do with the results before you begin the study

- Use the results in making a decision!

- Make plans for scaling-up a successful intervention 


\section{Manager's Role in Dissemination}

- Identify key audiences (e.g. service providers, Minister of Health, donors)

- Identify effective means of dissemination (e.g. seminars, presentation at annual meeting, newsletter)

- Help present results, be author on papers 


\section{Researcher's Role}

- Participates in problem identification

- Responsible for design and integrity of research

- Monitors implementation of research

- Analyzes results

- Keeps managers informed and involved

- Participates in dissemination

- Assists in results utilization 


\section{Characteristics of a Good Collaboration}

- Mutual trust and respect

- Frequent contacts to discuss progress

- Frank discussion of problems and attempts to solve problems 


\section{Contracting Research}




\section{What to Put in a Research Contract}

- Specific research objectives

- Time-line

- Itemized budget

- Methodology (sample design, variables)

- Fieldwork details: Qualifications, quality control, days in field

- Data analysis plan: Computer packages, data entry and cleaning, principal analyses

(2) Population Council FRONTIIERS 


\section{Deliverables Specified In Contract}

- Written report including executive summary

- Oral presentation

- Specified analyses

- All instruments including questionnaires, data collection forms, data dictionaries

- Copy of data-set 


\section{Session 4: Instructor's Guide Exercises: Using Data for Managerial Decision-Making}

\section{SESSION OBJECTIVES:}

- To test and reinforce participants knowledge of the difference between diagnostic and intervention studies

- To gain skill identifying research data immediately useful for program decisionmaking

- To develop awareness of appropriate and inappropriate types of managerial behavior in an operations research project

\section{POINTS TO EMPHASIZE:}

- The instructor should begin by having the participants list the main findings presented in the executive summary

- Participants often have trouble identifying data that is immediately and directly useful for decision-making

- In identifying immediately useful data, have participants explain what each data item is useful for

\section{SESSION METHOD:}

- Divide participants into small groups. Have groups report back on each exercise.

\section{EXERCISES:}

- Exercises are based on an actual HIVIAIDS Place Study in Uganda

- Exercise 1, The Place Study, is an example of a diagnostic study. Participants should give reasons why it is a diagnostic and not an intervention study.

- Exercise 1: Examples of immediately useful findings include the addresses of specific sites where people go to meet new sexual partners, willingness of proprietors to host HIV prevention activities, approximate number of persons at sites during peak hours, etc. The facilitator should ask the participants "You have limited resources. Where would you put the program?"

- Exercise 2: Groups should debate what the manager did correctly and incorrectly. Subsequently, facilitator should ask participants to debate what the manager should have done differently. 
DURATION: 2 hours

\section{Materials}

1. PowerPoint Presentation "Exercises Using Data for Managerial Decision-Making"

2. Handout: "Exercise 1: Uganda Place Study Executive Summary"

3. Handout: "Exercise 2: Actions of a Program Manager in an OR Project" 


\section{Using Data for Managerial Decision Making}

\section{Exercises}




\section{Exercise 1:}

- The purpose of the exercise is to identify data that is immediately useful for program design. Read the executive summary and decide how you would use the results presented.

- Is the study a diagnostic or an intervention study? 


\section{Exercise 2:}

- Read the case study and critique the behavior of the program manager.

- Did he use the results?

- What was correct in his behavior?

- What was incorrect? 


\title{
Session 4: Exercise 1 Uganda Place Study Executive Summary
}

Read the executive summary carefully, and be prepared to discuss the following:

1. Describe the methodology used in the study

2. Do you think this is an intervention study or diagnostic/formative research?

3. Summarize the main findings of the study

4. Identify data from the Place Study that can be used to guide specific program actions

\section{Executive Summary}

\begin{abstract}
Although HIV prevalence appears to be declining in Uganda, there is a need to identify geographic areas likely to have high incidence of HIV infection and to monitor the adequacy of AIDS prevention programs in those areas.
\end{abstract}

In mid-2000, researchers at the Institute of Public Health and the Department of Population Studies at Makerere University met with MEASURE/Evaluation staff to discuss the need for determining the adequacy of AIDS prevention programs in Kampala. Although AIDS prevention programs seek to cover the entire city, researchers thought that some pockets of the city were being missed by the general population campaigns and condom distribution programs. The PLACE protocol was considered an appropriate tool for identifying areas likely to have higher rates of HIV incidence and for monitoring prevention efforts in those areas. Funding for the assessment was provided by USAID through the MEASURE/.Evaluation project.

\section{What is the specific aim of the PLACE protocol?}

Because resources for HIV prevention programs are extremely limited, there is an urgent need to focus interventions where they are most cost-effective. To most cost-effectively prevent new infections, AIDS prevention programs should focus on areas likely to have a higher incidence of infection. The PLACE (Priorities for Local AIDS Control Efforts) method is a new monitoring tool to identify areas likely to have a higher incidence of infection (based on available epidemiologic and sociodemographic information) and to identify specific sites within these areas where AIDS prevention programs should be focused. Site-based indicators of sexual activity and AIDS prevention programs are provided by the method to monitor whether interventions are reaching key sexual networks in the city.

\section{A review of available data suggested that the incidence of HIV infection may be higher in the Kawempe Division of Kampala.}


Meetings were initially held with the AIDS Control Project (ACP) of the Ministry of Health and the AIDS Information Center (AIC) to identify areas where HIV incidence may be high in the city. The area that was selected for study is comprised of five adjacent parishes in the Kawempe Division of Kampala. This area has an elevated risk of sexually transmitted infections according to the AIDS Control Project of the Ministry of Health. It is also prone to epidemics of diarrhoea disease due to poor social and sanitary services. The area also has several active NGOs implementing HIV control interventions with sufficient capacity to address HIV control needs identified by the assessment.

Where do people from Kawempe District go to meet new sexual partners? 929 key informants identified 255 places-many more than anyone expected. Most of the sites are bars and taverns; sexwork is uncommon.

Trained interviewers talked with 929 key informants who identified 255 places where people from Kawempe District go to meet new sexual partners. Key informants included taxi drivers, motor mechanics, teachers, youth, and the police. About $30 \%$ of the sites were outside Kawempe Division and 173 were inside Kawempe Division.

Next, the interviewers visited all reported sites in the five study parishes. They obtained information about the site from a knowledgeable person onsite (such as a site manager or employee) for 169 of the 173 reported sites. Sites included bars and taverns $(62 \%)$, shops and video clubs (13\%), hotels and brothels (9\%), and churches $(3 \%)$. The size of a sites varied. About $40 \%$ of sites have fewer than 30 patrons during their busiest times; only $8 \%$ have more than 100 .

About half of those interviewed about the characteristics of the site and its patrons reported that men and women find new sexual partners at the site. Sex work was reported at fewer than $15 \%$ of sites.

Over $75 \%$ of individuals socializing at the sites reported that people meet new sexual partners at the site. About $30 \%$ reported having met a new sexual partner at the site.

In the final phase of field work, interviews were conducted with 1,114 individuals socializing at 81 of the 173 sites in Kawempe Division. The purpose of these interviews was to describe the characteristics and behavior of people socializing at the sites.

Most of the men and women socializing at the sites (60\%) were younger than 30 and only $30 \%$ were employed fulltime. Almost $80 \%$ lived in the study area and $40 \%$ visited the site daily.

Over $75 \%$ of those interviewed believed that people meet new sexual partners at the site. In fact, $29 \%$ of the men and $31 \%$ of the women interviewed reported having personally attracted a new partner at the site. About a fourth of those interviewed reported having met a previous sexual partner at the site. Altogether, $42 \%$ of those interviewed reported having met a new or previous sexual partner at the site; $20 \%$ reported meeting a new sexual partner at the site within the past six months. 
Most people had used a condom at least once in their lifetime. Condom use was more frequent in encounters involving commercial sex, but only $45 \%$ used a condom with their most recent partner.

Overall, $80 \%$ of the men and $72 \%$ of the women had ever used a condom. Condom use was more common in new partnerships and in partnerships involving commercial sex than in partnerships with boyfriends and girlfriends.

\section{AIDS prevention activities and condoms generally do not reach high risk sites, even though many site managers are willing to sell condoms on site and have AIDS prevention programs.}

In spite of the high rate of new partnership formation at the sites, only $33 \%$ of sites had ever had an AIDS prevention program onsite. Only $11 \%$ had an AIDS prevention poster visible. Only $20 \%$ had condoms available onsite at the time of the site visit; $69 \%$ of site managers reported that condoms were never available onsite. Almost all (95\%) of the site managers said they would be willing to have an AIDS prevention programme onsite and $61 \%$ were willing to sell condoms onsite.

\section{Program implications of the assessment:}

With strong community involvement, interventions need to be further focused on sites where new partners are met, while maintaining a strong general population prevention program, as overall levels of partner change are high.

This assessment identified gaps in AIDS prevention programming in five parishes in Kawempe Division of Kampala. Although the assessment did not provide biomedical evidence that the incidence of HIV infection is any higher in this area than elsewhere, the assessment suggests that the sexual network in the area could easily support an epidemic of HIV infection. The rates of new partner acquisition reported from individuals socializing at the sites are higher than the rate estimated necessary to sustain transmission of HIV, gonorrhea, chlamydia, or syphilis. Although most of the people socializing at sites of new partnership formation had used condoms, condom use in nonmarital partnerships was not

consistent.

AIDS prevention efforts should be focused at sites where people meet new sexual partners and especially where youth meet new sexual partners. Limiting AIDS prevention efforts to sites where sexwork is clearly evident will miss many important sites. Only 13 percent of those who reported engaging in paid sex were interviewed at sites where sex work was clearly evident.

The study found that most of the persons socialising in the sites where new sexual partner formation was reported were residents from the study area. Geographically based interventions are viable in fixing gaps in preventive programs. This is in line with local administrative action instead of national focus. 


\section{Summary of Indicators from Assessment}

\section{Number and Type of Sites}

Number of sites reported where people from Kawempe Division

meet new sexual partners

Percent of reported sites located in Kawempe

$68 \%$

Percent of 173 sites in Kawempe

- With commercial sex workers

- Percent of sites that are bars or taverns

$62 \%$

\section{AIDS Prevention Program Coverage}

Percent of Sites in Kawempe:

- That ever had HIVIAIDS programs

- Where manager willing to have program

$95 \%$

- Where condoms never available

$69 \%$

- With condoms available on day of visit

$20 \%$

- Where the manager is willing to sell condoms

$61 \%$

\section{Characteristics of People at Sites}

Percent Socializing at Sites Who:

Men Women

- $\quad$ Are younger than 25

- Visit the site every day

- Have met a new sexual partner at the site

- Had a new sexual partner in the past 3 months

- Who have ever used a condom

- Who used a condom the last time they had sex*

- Who used a condom with the most recent new partner**

- Who have attended an AIDS educational session

*of people with at least one partner in last three months and who have non-missing condom use data

${ }^{* *}$ of people with at least one new partner in last three months who have non-missing condom use data 


\section{Session 4: Exercise 2 The Program Manager Acts on the Place Study}

In the mid-1980's, Uganda had one of the highest HIV prevalence rates worldwide and was described as the epicentre of the AIDS pandemic. In the face of escalating prevalence in other parts of Africa, the Ugandan AIDS situation changed dramatically due to intense prevention efforts. Since 1997, prevalence rates have dropped from as high as $28.8 \%$ in 1991 to $6.1 \%$ in 2002 in antenatal sentinel sites, and Uganda is no longer listed among the ten countries with the highest prevalence rates in the world. Prevention interventions have included: aggressive I.E.C campaigns; support from the highest levels of government; an openness to HIVIAIDS information; acceptance of persons living with HIVIAIDS and large numbers of active NGOs such as The AIDS Support Organization (TASO) and the AIDS Information Centre (AIC).

The Medical Officer of Health of Kawempe Division who had been key in designing HIVIAIDS prevention interventions, however felt that there were still pockets of high transmission areas in Kawempe. He therefore solicited support from USAID to conduct a rapid assessment of AIDS prevention interventions in Kawempe in order to identify gaps in the prevention program. He commissioned researchers from the Institute of Public Health and the Department of Population Studies at Makerere University to conduct an evaluation. He met with the research team at the signing of the contract to hand over the cheque then went on an overdue leave of 2 months. He left instructions with his secretary that the report should be sent to USAID Washington when completed and a copy of the executive summary left on his desk.

When he returned from leave he found the attached executive summary on his desk as he had instructed.

1. Discuss the role that this program manager did or did not do.

2. If you were this program manager what steps would you take next? 


\section{Session 5: Instructor's Guide Identifying Problems and Solutions}

\section{SESSION OBJECTIVES:}

- To distinguish between a researchable problem and different types of program problems

\section{POINTS TO EMPHASIZE:}

- Defining the problem is the critical step in the OR process. If a problem cannot be clearly defined, all subsequent steps are wasted, and little or no useful data will be produced by the study

- There are differences between program problems and researchable problems

- Have all participants complete the OR problem statement (slide 11 on page 4)

- Program staff are one of the best sources of identifying problems and solutions, but other stakeholders should be consulted, especially clients.

SESSION METHOD: presentation/discussion

EXERCISES: There is one exercise (practice stating an OR problem). The exercise should be heavily emphasized during the session

DURATION: 1 hour

\section{Materials}

1. PowerPoint Presentation: "Identifying Problems and Solutions" 


\section{Identifying Problems and Solutions}




\section{What is a Problem?}

- OR begins with a problem to be solved

- A program problem is a discrepancy between actual and desired results 


\section{Problems and Opportunities}

- Not all problems mean something is wrong with the program. Some problems are opportunities, e.g.,

"What is the best way to increase the size of this program to serve more people?" 


\section{Identifying a Program Problem}

- Is the problem under managers' control?

- Is it possible to develop a feasible, effective, and sustainable intervention?

- Will solution improve outputs, outcomes, impacts or efficiency? 


\section{Is the Problem Researchable?}

- Is there a discrepancy between actual and desired results?

- Do I need research to solve the problem ?

- Do I have enough time, money and qualified research staff? 


\section{Non-Researchable and Researchable Problems}

Non-Research

- A discrepancy exists between desired and observed situation

- We know why the discrepancy exists

- We know the best solution
Research

- A discrepancy exists between desired and observed situation

- We do not know why the discrepancy exists

- different solutions exist but we do not know the best one
(P) Population Council FRONTIERS 


\section{In Operations Research the manager intervenes in inputs and processes to solve problems}




\section{An OR problem is a programmatic problem restated as a question.}




\section{Examples of OR Problems}

- If I charge 10 pesos for a pap smear, will fewer women get pap smears?

- Will training community health workers increase vaccination coverage?

- Will a mass media campaign attract more women to deliver in hospitals? 


\section{Practice stating an OR problem}

- Make a problem statement using the format:
Will (increasing, decreasing, changing) this (input or process) improve (output, outcome or impact)? 


\section{Start with the problem not the solution}

- Do you actually have the problem that this intervention is intended to solve?

- Is the "solution" best way to solve your problem?

$>$ Always diagnose the problem thoroughly before identifying the intervention(s) to address it 


\section{Identifying the Solution}

- Every OR problem has to have more than one solution

- If there is only one solution, research is not necessary 


\section{Characteristics of a Good Solution}

- Under control of manager

- Has potential to make large improvement

- Effects can be measured

- Easy to implement

- Affordable/sustainable 


\section{Sources of Solutions}

- Program staff

- Clients

- Staff of other programs

- Policies

- Literature review

- Researchers 


\section{Session 6: Instructor's Guide Exercises: Problems and Solutions}

\section{SESSION OBJECTIVES:}

- To reinforce participants' knowledge of the information presented in session 5

\section{POINTS TO EMPHASIZE:}

- There is a difference between problems, program problems, and researchable problems

- To be worth researching, a problem must have more than one potential solution

\section{SESSION METHOD:}

- Participants should be divided into small groups. Each group should be assigned two or more exercises to work on. The conclusions of each group/exercise should be discussed in the large group.

- All groups should do exercise 8 .

DURATION: 1 hour

\section{Materials}

1. PowerPoint presentation: "Problems and Solutions Exercises"

2. Handout: "Exercise 1: The Operations Research Paradigm" 


\section{Problems and Solutions}

\section{Exercises}




\section{Exercise 1}

- Youth centers exist all over Africa. How can we start one in our country?

- Are youth centers a problem or a solution?

- What problems might a youth center address?

- Give some alternatives to youth centers for reaching young people. 


\section{Exercise 2}

- The supplies have not arrived. The bridge has been washed away by rains.

- Is this an OR problem? Why/Why not?

- Is there more than one solution to the problem?

-What are the possible solutions? 


\section{Exercise 3}

- Women in Country X follow the cultural norm of a 40-day seclusion for post-partum mothers. As a result they do not seek care when needed.

- Is this a program problem?

- What are some possible solutions? 


\section{Exercise 4}

- Men in district $Y$ have high levels of HIV.

- Condom use is also low.

- Is this an OR problem?

- Give two possible solutions

- What outputs, outcomes, and impacts would you measure to see if the solution was effective? 


\section{Exercise 5}

- We are having a polio outbreak because our vaccination coverage is incomplete

- What problems in inputs and processes might be causing this problem

- Identify potential solutions

- Restate the problem as an OR question 


\section{Exercise 6}

- Name 2 characteristics of a good solution.

- Name 3 inputs under the control of a manager.

- Name 2 processes under the control of a manager.

- How can I decide if a problem is researchable? 


\section{Exercise 7:}

\section{Identify the OR problem statement}

-We are having a cholera outbreak!

- Adolescents are having sex!

- Let's study positive deviants.

- Will decreasing the frequency of supervision improve efficiency without reducing service quality? 


\section{Session 6: Exercise 1 The Operations Research Paradigm}

Manipulate a factor (program element) under the control of a manager to help you reach your objective:

A. For each program objective, select one program element that you would change to try to improve the problem identified.

B. Mark the Element with an X for each objective.

C. Explain why you selected that program element to manipulate, and how you would manipulate it.

\begin{tabular}{|l|l|l|l|}
\hline & \multicolumn{3}{|l|}{ PROGRAM OBJECTIVE } \\
\hline $\begin{array}{l}\text { PROGRAM } \\
\text { ELEMENT }\end{array}$ & $\begin{array}{l}\text { ACCESS: } \\
\text { (More people come } \\
\text { to the clinic) }\end{array}$ & $\begin{array}{l}\text { EFFICIENCY } \\
\text { (Lower cost per } \\
\text { service produced) }\end{array}$ & $\begin{array}{l}\text { QUALITY } \\
\text { (Providers give } \\
\text { enough information } \\
\text { to allow the client to } \\
\text { take his medicine } \\
\text { correctly) }\end{array}$ \\
\hline Training & & & \\
\hline Supervision & & & \\
\hline Counseling & & & \\
\hline Logistics & & & \\
\hline $\begin{array}{l}\text { Personnel } \\
\text { (Salaries, Hiring } \\
\text { and firing) }\end{array}$ & & & \\
\hline Pricing & & & \\
\hline Promotion & & & \\
\hline Norms & & & \\
\hline
\end{tabular}




\section{Session 7: Instructor's Guide Causality}

\section{SESSION OBJECTIVES:}

- To explain the concept of causality in the context of OR

- To introduce some of the designs that can demonstrate causality ("true experimental designs") most often used in OR

POINTS TO EMPHASIZE:

- Symbols used in describing an experimental design

- Requirements for demonstrating causality

- Characteristics of an experimental design

- The basic pretest-posttest two group design with random assignment

- The importance of distinguishing between statistical significance and practical importance

\section{SESSION METHOD:}

- Lecture/discussion

\section{EXERCISES:}

DURATION: 2 hours

\section{Materials}

1. PowerPoint presentation: "Causality" 


\section{Causality}




\section{Causality}

\section{when one event produces a second event}




\section{Why Study Causality?}

- We are making program decisions to maintain, expand or discard the intervention and need evidence that the intervention, rather than some other factor, caused the observed change. 


\section{Causality Requirements}

- A (intervention) precedes B (outcome)

- $B$ is present only when $A$ is present

- We can rule out all other possible "causes" 


\section{The Basic Experimental Principle}

- The intervention is the only difference between set of observations/groups

- This is achieved by random assignment 


\section{The Gold Standard}

- An experimental design with random assignment is the gold standard for demonstrating causality

- Required by FDA to license drugs 


\title{
Symbols
}

$\mathrm{O}=$ Observation

$\mathrm{X}=$ Intervention

$\mathrm{RA}=$ Random Assignment

\author{
Independent Variable $=\mathrm{X}$
}

Dependent Variable $=0$ 


\title{
Basic Experimental Design
}

\author{
experimental group: $\mathrm{O} 1 \times \mathrm{O} 2$
}

RA
control group:
$\mathrm{O} 3$
$\mathrm{O} 4$ 


\section{Characteristics of an Experimental Design}

- Manipulation of intervention

- Comparison of experimental and control groups

- Control of threats to validity

- Random assignment

- Matching 


\section{Random Assignment}

- Random sampling: In surveys, random sampling ensures that individuals in the study are truly representative of the population from which they are drawn.

- Random assignment: In experiments, random assignment ensures that the experimental and control groups are truly comparable. 


\section{Matching}

- OR often uses small numbers of experimental units

- Matching improves the equivalence of small groups

- Units are matched on an initial measure prior to the experiment

- Is done prior to random assignment

- Is done purposively (researcher selects factor on which pairs will be matched) 


\section{Limitations of Random Assignment}

Random assignment does not protect against bias caused by:

- Contamination

- Very small number of units 


\section{Units of Study in OR}

- Units of study in OR can be individuals: clients, providers, the general public

- Units of study can be groups: facilities (hospitals, wards, clinics) villages, districts 


\section{Causal Comparisons}
$\mathrm{O} 1=\mathrm{O} 3$
$01 \neq 02$
$\mathrm{O} 2 \neq \mathrm{O} 4$
$\mathrm{O} 3=\mathrm{O} 4$ 


\title{
Post-test Only Control Group Design
}

\author{
$\mathrm{XO}$
}

RA 


\section{Comparison of Post-test/Pre- test with Post-test Only Design}

- Post-test Only is cheaper and quicker

- All else being equal, post-test/pre-test designs are preferred:

- Allow us to measure amount of change

- Permits matching 


\section{Two Multiple Group Designs (Random Assignment)}

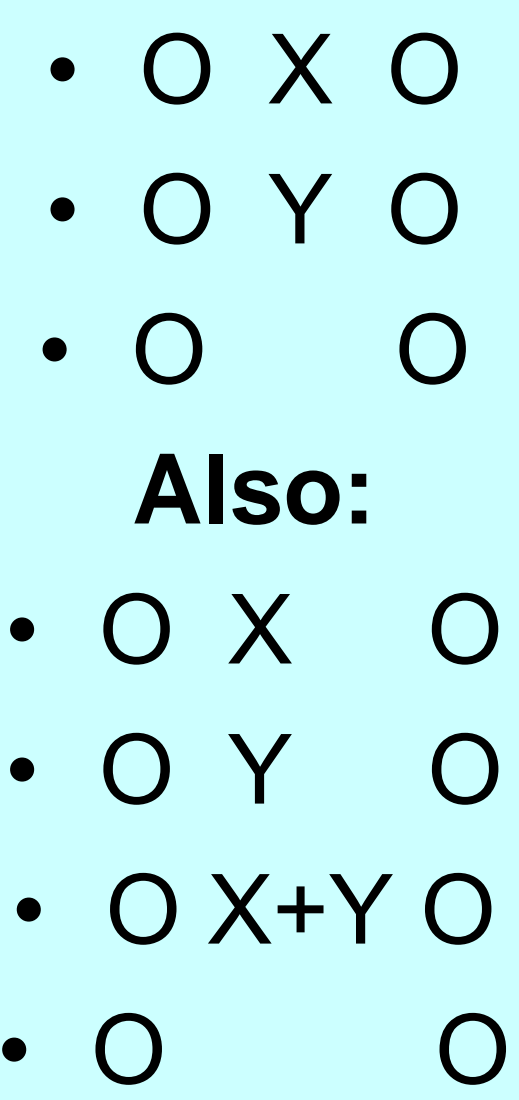




\section{Multiple Group Designs}

- An efficient way to test more than one solution

- Best design to study integration of services 


\section{Statistics}

- Used to determine if differences between groups are greater than could be expected by chance alone

- Are the differences "real"? 


\section{Statistical Significance and Practical Importance}

- Statistical significance does not imply that the result is important.

- A conservative approach to interpreting data:

- If result is not statistically significant STOP

- If result is statistically significant ask is the difference PRACTICALLY IMPORTANT?

(P) Population Council FRONTIERS

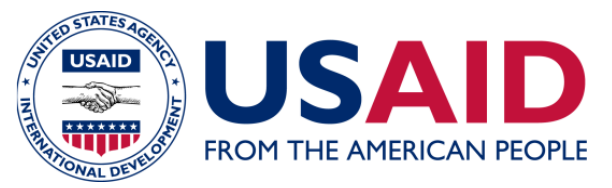




\section{Commonly Used Statistics}

- Cross-tabulation

- Chi Square (compares distributions-used with cross-tabs)

- Z-test (compares 2 proportions)

- T-test (Compares 2 means)

- F-test (Compares more than 2 means) 


\section{Statistical Significance}

- States the probability that difference between groups is greater than chance ('real')

- Function of sample size and strength of intervention

- Conventions:

$$
\begin{aligned}
& p<.05=1 \text { chance in_ that the difference is not real } \\
& p<.01=1 \text { chance in_ that the difference is not real } \\
& p<.50=1 \text { chance in_ that the difference is not real }
\end{aligned}
$$




\section{Operational Definitions}

Terms and variables must be defined in a way that permits measurement and monitoring.

- No: "The independent variable is group counseling"

- Yes: "Groups < 8 persons meet 2 hrs/day for 3 consecutive days. Topics include What is HIV? (45 minutes)...." 


\section{Session 8: Instructor's Guide Quasi- and Non-Experimental Designs}

\section{SESSION OBJECTIVES:}

- To explain the concepts of reliability and validity

- To introduce participants to frequently used Quasi- and Non-experimental designs

- To familiarize participants with the appropriate uses, strengths and weaknesses of Quasi- and Non-experimental designs

\section{POINTS TO EMPHASIZE:}

- It is not always possible to use a true experimental design

- Although, technically, Quasi- and Non-experimental designs do not demonstrate causality they can provide strong evidence for the effect of an intervention

- Selection of a design depends on when the manager must have the information, what resources are available for the study, and the degree of precision needed in the data

SESSION METHOD: Lecture/discussion

EXERCISES:

DURATION: 2 hours

\section{Materials}

1. PowerPoint Presentation: "Quasi- and Non-Experimental Designs" 


\section{Quasi- and Non- Experimental Designs}




\section{Difference Between Quasi- and True Experimental Designs}

- A true experimental design uses random assignment to protect against sources of invalidity.

- A quasi-experimental design does not use random assignment and cannot protect against many types of invalidity.

- A true experimental design demonstrates causality; a quasi-experimental design does not.

(P) Population Council FRONTIERS

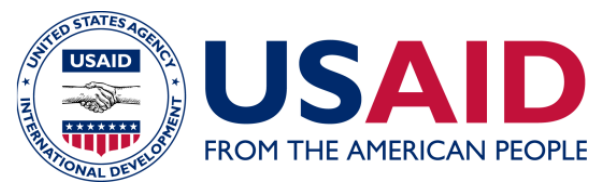




\section{You Cannot Always Use an Experimental Design}

- Units cannot be randomly assigned to organismic variables

- You may have a very small sample

- Political, ethical and administrative reasons: (e.g No one would randomly assign a public health program)

- Fear of contamination may prevent random assignment

(P) Population Council FRONTIERS 


\section{Precision Affects Design Selection}

- If serious negative consequences can result from making a wrong decision based on the experiment, the stronger the design must be.

- If results of a wrong decision will not be serious, weaker designs may be used. 


\section{Potential Weaknesses of Quasi- and Non-experimental Designs}




\section{Reliability}

Reliability refers to the consistency and dependability of the data.

A reliable measure if repeated a second time will give the same results as the first time

- If I ask the same person the same question twice, will I get the same answer?

- Types of reliability: Test-retest; inter-rater, consistency 


\section{Validity}

- Validity refers to measurements that are not only reliable but also true and accurate

- A valid measurement measures what it is supposed to measure

- A valid measure is also reliable

- A reliable measure is not always valid 


\section{Validity Concerns}

- Internal validity: Did the experimental treatment make a difference in this specific study?

- External validity: To what programs, settings and populations can the results of the study be generalized? 


\section{Factors Commonly Jeopardizing Internal Validity in OR Studies}

- Selection Bias

- History

- Testing

- Differential Mortality 


\section{Selection Bias}

- Selection bias occurs whenever the people selected for the control group differ systematically from the experimental group

- Self-selection into groups is a common problem in operations research studies 


\section{History}

\section{Some things happen to one group that do not happen to the comparison group}

- Strikes

- New procedures

- A presidential address 


\section{Testing}

Testing bias occurs when earlier measurements affect the results of later measurements.

- Giving identical pre-tests and post-tests to trainees

- Repeatedly interviewing the same participants in the study 


\section{Differential Mortality}

If the people/units who drop out of one study group differ systematically from drop outs of the other group, we do not know if results are due to intervention or differential mortality. 


\section{Quasi-Experimental Designs}

\section{Uses of different quasi-experimental designs and validity threats}




\section{Time Series Design}

- Repeated measures on the same group over time

- No control or comparison group

$$
\mathrm{O}_{1} \mathrm{O}_{2} \mathrm{O}_{3} \times \mathrm{O}_{4} \mathrm{O}_{5} \mathrm{O}_{6}
$$




\section{Did the Intervention Have an Effect?}

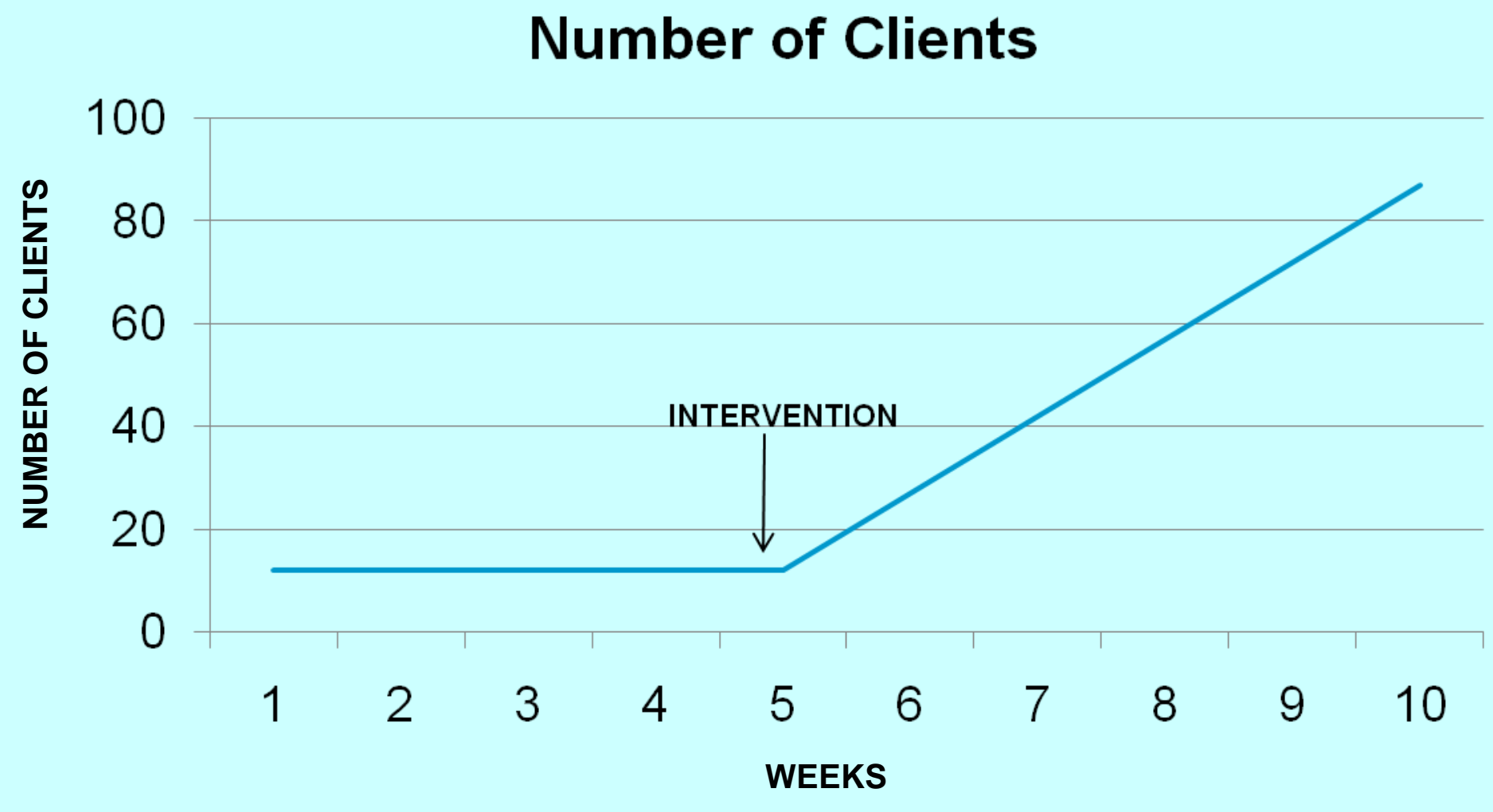




\section{Did the Intervention Have an Effect?}

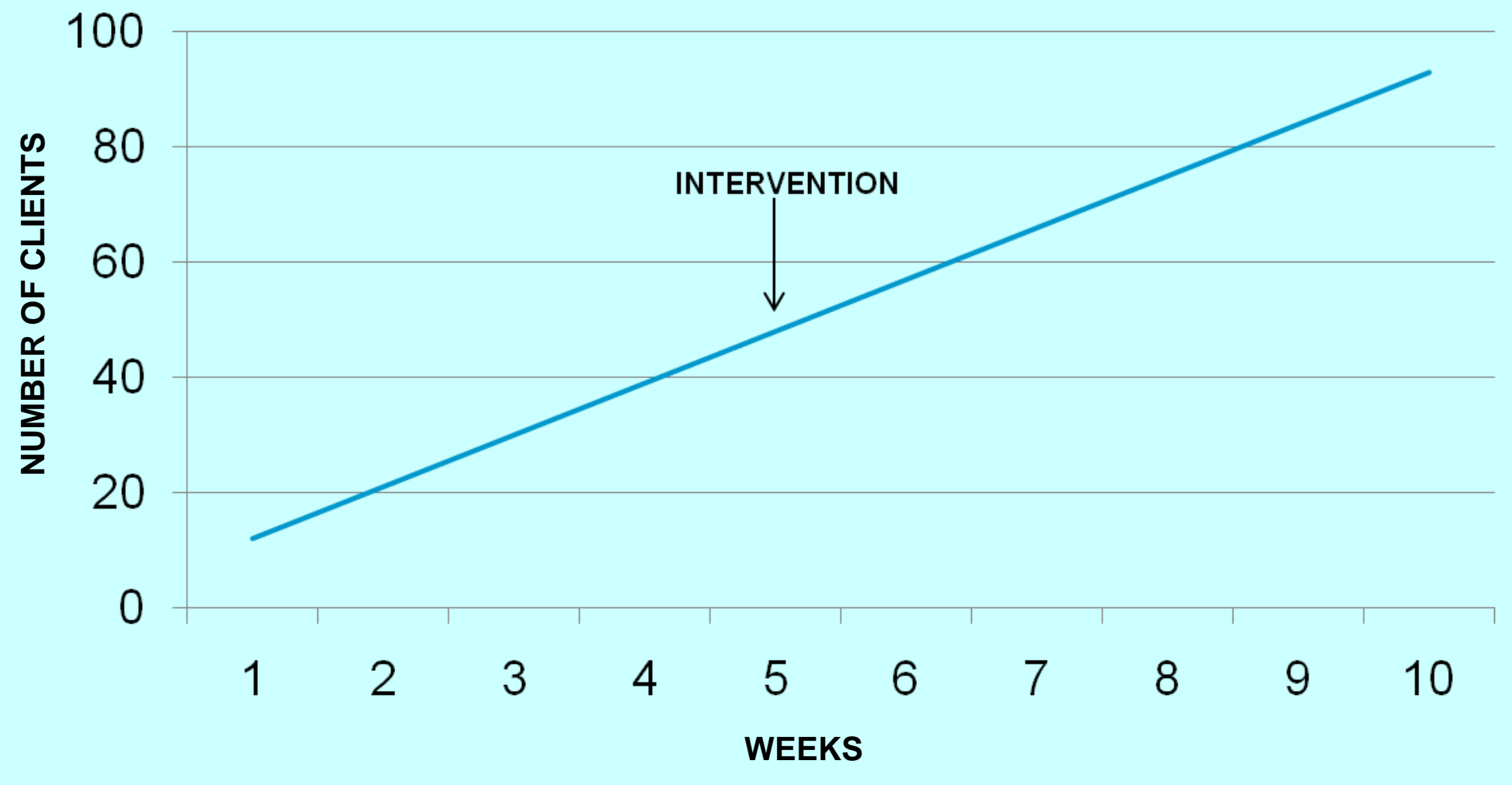




\section{Use of Time Series Designs}

- Evaluate a mass media campaign

- Whenever you cannot use a separate control group (e.g., only one facility in the study) 


\section{Validity Threats in a Time Series Design}

A time series design does not control for:

- History

- Testing 


\section{Pre-test/Post-test Non-equivalent Control Group Design}

- Intervention and comparison groups

- No random assignment

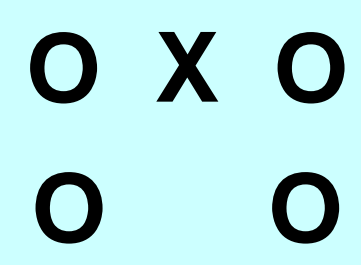




\section{Use of Non-equivalent Control Group Design}

- When you have no more than two units to assign (e.g., two hospitals, two districts)

- When random assignment is not possible

- Study units should always be matched in a non-equivalent control group design 


\section{Validity Threats in a Non-equivalent Design}

A non-equivalent design does not control for:

- Selection

A non-equivalent design does control for:

- History

- Testing 


\section{Non-experimental Designs}

- Case Study: No control for invalidity

$\mathrm{X} \mathrm{O}$

-used in test marketing/focus groups

- One Group Pre-test/Post-test: No control for history, testing

$\mathrm{O} \times \mathrm{O}$

- used in evaluations 


\section{Strengthen the Case for Your Design with Evidence}

- No random assignment - Any evidence of systematic bias in the selection?

- Time series study - Any historical event that may have influenced the results? 


\section{Session 9: Instructor's Guide Exercises: Research Design}

\section{SESSION OBJECTIVES:}

- $\quad$ To reinforce the concepts presented in sessions 7 and 8

\section{POINTS TO EMPHASIZE:}

- Importance of operational definitions

- Most problems can be addressed by more than one research design

- Vocabulary and understanding of meaning of variables, names of designs, methods of assignment

\section{SESSION METHOD:}

- Participants should be organized into small groups and each group given at least two of each type of exercise (e.g. exercises on slides 1-3 require participants to operationally define independent variables; $5-14$ to use alternative research designs to solve a problem)

- The session requires an easel with paper so that participants can diagram research designs in front of the large group. Different participants should diagram the alternative research designs. Large groups should discuss strengths and weaknesses of each, using vocabulary introduced into earlier sessions.

EXERCISES: See session method above

DURATION: 2 hours

\section{Materials}

1. PowerPoint presentation: "Research Design Exercise" 


\section{Research Design}

\section{Exercises}




\section{Exercise 1}

- A study will compare the effect of increasing time devoted to sex education from 3 hours to 18 hours

- Operationally define the underlined terms in hypothesis:

Adolescent boys will use more condoms if they receive more sex education. 


\section{Exercise 2:}

\section{Operationally Define These Terms}

- Client satisfaction

- Quality of care

- High Risk Group

$>$ If you can't define it, you can't measure it, and you don't know what it is. 


\section{Exercise 3: Operationally Define the Independent Variable}

The independent variable is a training course for supervisors that will improve their knowledge of malaria.

a. What terms need to be operationally defined?

b. Define them 


\section{Exercise 4: \\ Research Design}

The $\mathrm{MOH}$ wishes to conduct a mass media campaign to promote use of treated bed nets

a.What designs can you use?

b.State an output indicator.

c.State an outcome indicator.

d.State an impact indicator. 


\section{Exercise 5: \\ Research Design}

What designs would you recommend to test the hypothesis that women who deliver in hospitals and are offered post-partum family planning services are more likely to use family planning than women not offered services?

a.State some possible dependent variables. b.What designs can you use?

c.What factors need to be operationally defined?

(P) Population Council FRONTIERS 


\section{Exercise 6 \\ Research Design}

The hospital is not available for your study, but you can use 10 health centers, each with a maternity ward.

a. Can you randomly assign?

b. Would you match? Why? What factors would you match on?

c. What design will you use if you cannot randomly assign? 


\section{Exercise 7 \\ Research Design}

A program may add injectables to family planning methods offered.

- Some think injectables can be made available through community health workers (CHWs), arguing it will increase rural contraceptive prevalence

- Others believe the risks of allowing CHWs to provide DMPA (poor infection prevention and counseling) outweigh increases in prevalence 


\section{Exercise 7: Questions}

- How many problems?

- How many dependent variables? What are they?

-What design would you use to compare these two points of view?

- Can you use random assignment? 


\section{Exercise 8 \\ Research Design}

The Minister of Health wants to know the following about the WHO/Focused Ante-Natal

Care (FANC) Package before adopting it country-wide:

1. Will women make the four scheduled visits?

2. Will there be an impact on health status? 


\section{Exercise 8: Questions}

a. Name designs to answer question 1 and give advantages and disadvantages of each

b. Name designs to answer question 2 and give advantages and disadvantages of each 


\section{Exercise 9: \\ Research Design}

- A new anti-malarial drug is available, but is complicated to administer. The program needs to know if patients must be kept in the hospital for three days to ensure compliance or if they will be able to complete treatment at home without supervision.

- 3 days of hospitalization maximizes correct use but is very expensive, and can be made available to few patients.

- Home treatment maximizes availability but increases possibility of incomplete treatment, low cure rates and development of drug resistant malaria strains

(P) Population Council FRONTIERS 


\section{Exercise 9: Questions}

a. Does the problem require high or low precision in the design?

b. What are the independent variables?

c. Name a possible dependent variable.

d. What designs would you use? 


\section{Exercise 10: Research Design}

The government TB control program wishes to know if enrolling private doctors into the program is feasible

a. Identify dependent variables

b. What design would you use? 


\section{Session 10: Instructor's Guide Implementing the OR Study}

\section{SESSION OBJECTIVES:}

- Present essential activities during the implementation of an intervention study

POINTS TO EMPHASIZE:

- Emphasize that both the intervention and the data collection activities must be closely monitored to guarantee the validity of the study results

- A data analysis plan must be drafted before the study begins - it is essential that the study team knows how the data will be analyzed.

\section{SESSION METHOD:}

- Lecture/discussion

\section{EXERCISES:}

DURATION: 1 hour

\section{Materials}

1. PowerPoint presentation: "Implementing the OR Study" 


\section{Implementing the OR Study}




\section{Planning Research Activities}

- Planning should begin during proposal writing

- Produce a detailed activity and monitoring plan (who, what, when,how)

- Include all activities

- Break activities into sub-activities

- Delegate responsibilities

- Plan should be group effort

- All team members should have copy of plan

(P) Population Council FRONTIERS

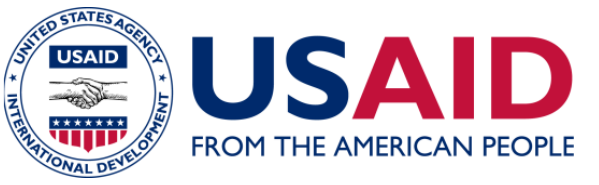




\section{Monitor The Intervention}

- Is intervention implemented as planned?

- Is intervention conducted equally in all units?

- Any evidence of contamination?

- Do groups remain equivalent?

- Are observations collected?

Without being able to say that the intervention was conducted as planned, you cannot say that the results are due to the intervention 


\section{Intervention Monitoring Questions: Example}

- The intervention is group counseling.

- Operational definition: Groups > 8 persons meet 2 hrs/day for 3 consecutive days. Topics include What is HIV? (45 minutes)....

Monitoring Questions:

- Did the groups meet for 2 hours?

- Were all topics covered?

- Where there more than 8 persons?

(2) Population Council FRONTIERS 


\section{Develop Data Collection Instruments Carefully}

- Instrument should measure what it is supposed to measure

- Common mistakes

- Failure to pre-test instrument

- Failure to provide a users manual

- Failure to train users/interviewers properly

- Use of ambiguous questions/double barrel questions

- Difficult/missing skip patterns

- Faulty translation of instrument

- Too long/too complicated 


\section{Data Collection Issues}

- Is data being collected according to study's ethical procedures?

- Is data being collected according to data collection plans?

- Is quality of the raw data acceptable? 


\section{Monitoring Data Collection}

- Regular field visits to supervise data collection

- Check first two days work and repeat training to correct data collection problems

- Provide staff with regular feedback on quality and completeness of data

- Examine samples of completed instruments 


\section{Data Management}

- Name and label all variables

- Have a data dictionary/code book/copies of instrument

- Make sure data is stored according to ethical guidelines

- Use a standard data base (Excel, SPSS, etc.)

- Use double data entry

- Perform range and consistency checks

- Save data dictionaries/instruments and data set

(P) Population Council FRONTIERS 


\section{Data Analysis}

- Have an analysis plan

- Use well-known data analysis software

- Examine your data before starting analysis (frequencies)

- Limited number of cross-tabs

- Time/date stamp output so you don't get confused

- Look at syntax: Is analysis correct? 


\section{Final Report Format}

- Abstract or summary

- Introduction

- Methods

- Discussion/Conclusions

- Recommendations (if any)

- References

- Appendixes 


\section{Session 11: Instructor's Guide Exercise: OR Study Implementation}

\section{SESSION OBJECTIVES:}

- To strengthen participants' knowledge of concepts introduced in session 10

\section{POINTS TO EMPHASIZE:}

- The first five exercises emphasize (1) sources of the data to be gathered, (2) the need to write clear survey questions, (3) how data are cleaned, (4) supervision and (5) data collection strategies. The correct answers to these exercises are given on the answer sheet below.

- Exercise 5 deals with a health center director who is not participating in the study as required. Asking the higher level manager who is collaborating in this study to intervene with the director should be one of the alternatives that participants mention.

\section{SESSION METHOD:}

- Large group exercise

\section{EXERCISES:}

- See above

DURATION: 1 hour

\section{Materials}

1. PowerPoint presentation: "OR Study Implementation Exercises"

2. Handout: "Session 11 Answer Sheet" 


\section{OR Study Implementation}

\section{Exercises}




\section{Exercise 1:}

\section{Where Would You Get the Data?}

- Number of patients receiving DOTS

- \% of children sleeping under bednets

- \% of women infected with HIV

- Number of condoms distributed in health centers

- Providers' knowledge of DOTS protocol

- \% of women using a family planning method

(2) Population Council FRONTIIERS 


\section{Exercise 2: Improve the Questions}

- "Were you treated politely by the doctor and the nurse?"

- "Do you believe that the evil behavior of female circumcision should be stopped?"

- "How would you rate the quality of the service you received?"

- "Do you usually use condoms?" 


\section{Exercise 3: Data Cleaning}

- There are three possible answers to a question: 1. Yes; 2. No; 3. Not sure. The data clerk entered the following numbers. Is there a problem? If so, how would you correct it?

- $2,3,1,1,2,1,3,2,2,9,1,1,1,3,2,4,3,3,1,2$ 


\section{Exercise 4: \\ Fieldwork Supervision}

- What action would you take?

- The survey interviews women 15-44 years of age. At the end of the day you find that the ages of women interviewed by an interviewer are all 25 years old.

- An interviewer completed 10 interviews and only finished half of 2 other interviews because the women had to pick up their children from school.

- Every two days your survey team moves to another village. How frequently would you have the supervisor review the completed questionnaires? Every night? Every other night? Once per week? Twice per day? 


\section{Exercise 5: \\ Data Collection Strategies}

- You want to find out how clinic clients are treated. You have three options. Name pros and cons of each.

- Interview all clients who come on a specific day

- Randomly select one out of every three clients who come on a specific day

- Have the interviewer choose 25 clients to interview over a two day period 


\section{Exercise 6: \\ What Should You Do?}

You are a researcher in charge of an OR study. Before the OR began, all health center directors attended an orientation where the study was explained, and the role of each center was specified. You make a supervisory visit and discover that one center is not participating. The director tells you he is too busy to participate. 


\section{Session 11: Handout Answer Sheet}

\section{EXERCISE 1: Where would you get the data?}

- Number of patients receiving dots: Clinic records

- $\%$ of children sleeping under bednets: Household survey

- \% of women infected with HIV: Household survey (saliva test); facility based sentinel system (blood test)

- Number of condoms distributed in health centers: Health center records

- Provider's knowledge of dots protocol: Test, observation

- $\%$ of women using a family planning method: Household survey

\section{EXERCISE 2: Improve the questions}

- Problem: Two questions in one. Change to two questions.

- Problem: Leading question. Take out "evil behavior".

- Problem: Definition of quality not given. Varies from person to person. Define quality.

- Problem: Definition of usually not given. Define usually.

\section{EXERCISE 3: Data cleaning}

- The series contains a 9 and a 4 when only 1-3 should appear. Discard the 9 and 4.

\section{EXERCISE 4: Fieldwork supervision: What action would you take?}

There are no "correct" answers to exercise four. Have participants discuss alternative possibilities.

\section{EXERCISE 5: Data collection strategies}

- Interview all clients: Pro: Larger number of interviews, get all types of clients who come. Con: Day may not be typical.

- Randomly select 1 of 3 clients: Pro: May be less expensive in a large clinic, less disruptive to clinic activities. Con: May not get enough interviews.

- Have the interviewer choose the clients: No pros, all cons. Interviewer may choose a biased sample. Specific instructions must always be given to interviewers. Either teach them to select random individuals, or give them the specific profile of the type of person you want interviewed (e.g. 25 women who are between 20-29 years old, are accompanied by one child less than 13 months old who has come for a vaccination. 


\section{Session 12: Instructor's Guide Dissemination of OR Results}

\section{SESSION OBJECTIVES:}

- To define the function of dissemination in operations research

- To provide examples of the contents of a dissemination plan

\section{POINTS TO EMPHASIZE:}

- The reason for disseminating the results of an OR study is to provide information for decision-making

- A dissemination plan and budget should be drafted before the OR study begins

- There are usually several audiences for the results of an OR project. Each audience may require a different dissemination approach

\section{SESSION METHOD:}

Lecture/Discussion

EXERCISES:

DURATION: 1 hour

\section{Materials}

1. PowerPoint presentation: "Dissemination of OR Results" 


\section{Dissemination of OR Results}




\section{Dissemination}

- A continuous process of systematically communicating research information

- Planned, coordinated, and under the control of managers and researchers 


\section{Dissemination: Goal and Strategy}

- Goal: to provide accurate information for decision making understandably and convincingly

-Dissemination strategy depends on the utilization strategy 


\section{The Dissemination Plan}

- Prepared prior to implementing research

- Identifies key audiences, messages, communication channels, specific activities, and products

- Part of every OR proposal 


\section{Identifying Key Audiences}

-Who makes what decision?

-Why they are important? (if not directly involved in decision making)

-Where are they?

-What is the best way to reach them? 


\section{Some Key Audiences}

- Program decision makers

- Donors and TA organizations

- Other programs

- Service providers and managers

- Communities

- Media

Each audience has specific informational needs. Audiences must be prioritized. 


\section{Messages}

- What kind of information do the audiences need?

- Identify key messages for each important audience.

- Make sure your message is simple, relevant, and practical. 


\section{Creating a Dissemination Strategy: How to Say It}

Determine the best channels for different audiences:

- Printed reports and summaries

- Presentations

- Mass media

- Professional journals

- One-on-one meetings 


\section{Session 13: Instructor's Guide Research Ethics}

\section{SESSION OBJECTIVES:}

- To present the rules of ethical conduct in research

POINTS TO EMPHASIZE:

- All research involving human subjects is subject to ethical guidelines

- The three principals of research ethics

- Ethical rules

- Institutional Review Boards (IRB)

- Informed Consent

- Call attention to the Handout. Participants can use it after the workshop has ended to help them with human subjects questions.

\section{SESSION METHOD:}

- Lecture/Discussion

\section{EXERCISES:}

DURATION: 1 hour

\section{Materials}

1. PowerPoint presentation: "Research Ethics"

2. Handout: "Guide for Interpreting the Federal Policy for the Protection of Human Subjects" 


\section{Research Ethics}




\section{Research}

- Systematic investigation designed to produce generalizable knowledge (to other populations or situations)

Types of research:

- Research on humans (person is study unit)

- Health care systems research including most OR (system is study unit)

- Human and systems research often have different levels of research review

(2) Population Council FRONTIERS 


\section{Research Participants}

- Living individuals from whom the researcher may obtain data

- Through interaction (e.g., surveys) or intervention (e.g., blood test)

- Identifiable private information (e.g., medical records) 


\section{Principles of Research Ethics}

- Respect for persons: Voluntary and informed consent and protection of vulnerable populations

- Beneficence: Possible benefit to participant maximized, possible harm minimized

- Justice: Fair and equitable division of research burdens and benefits 


\section{Ethical Abuses Lead to Codes}

- Nazi science (1933 - 1945)

- Tuskeegee Syphilis study $(1932-1972)$ 


\section{Principal Ethics Codes}

- Nuremberg code

- Declaration of Helsinki

- Belmont report

- Common rule 


\section{Ethical Rules Derive From Codes}

- Well being of subject takes precedence

- Written informed consent

- Participant free to stop at anytime

- Research approved by ethics committee

- Sensitive data on individuals protected

- Continuing review of approved research 


\section{Ethical Review by Institutional Review Boards (IRB)}

- Self review by researcher or manager not sufficient for compliance with letter or spirit of ethical review

- IRB must be registered with government

- Research may be subject to review by more than one IRB

- Review board in host country, review board in country of research group

- IRB in country of research group must have knowledge of host country relevant to research (e.g. for a microbicide study in Thailand, knowledge of laws governing sex work)

- Research must be approved by all boards

(P) Population Council FRONTIERS 


\section{IRB Fundamentals}




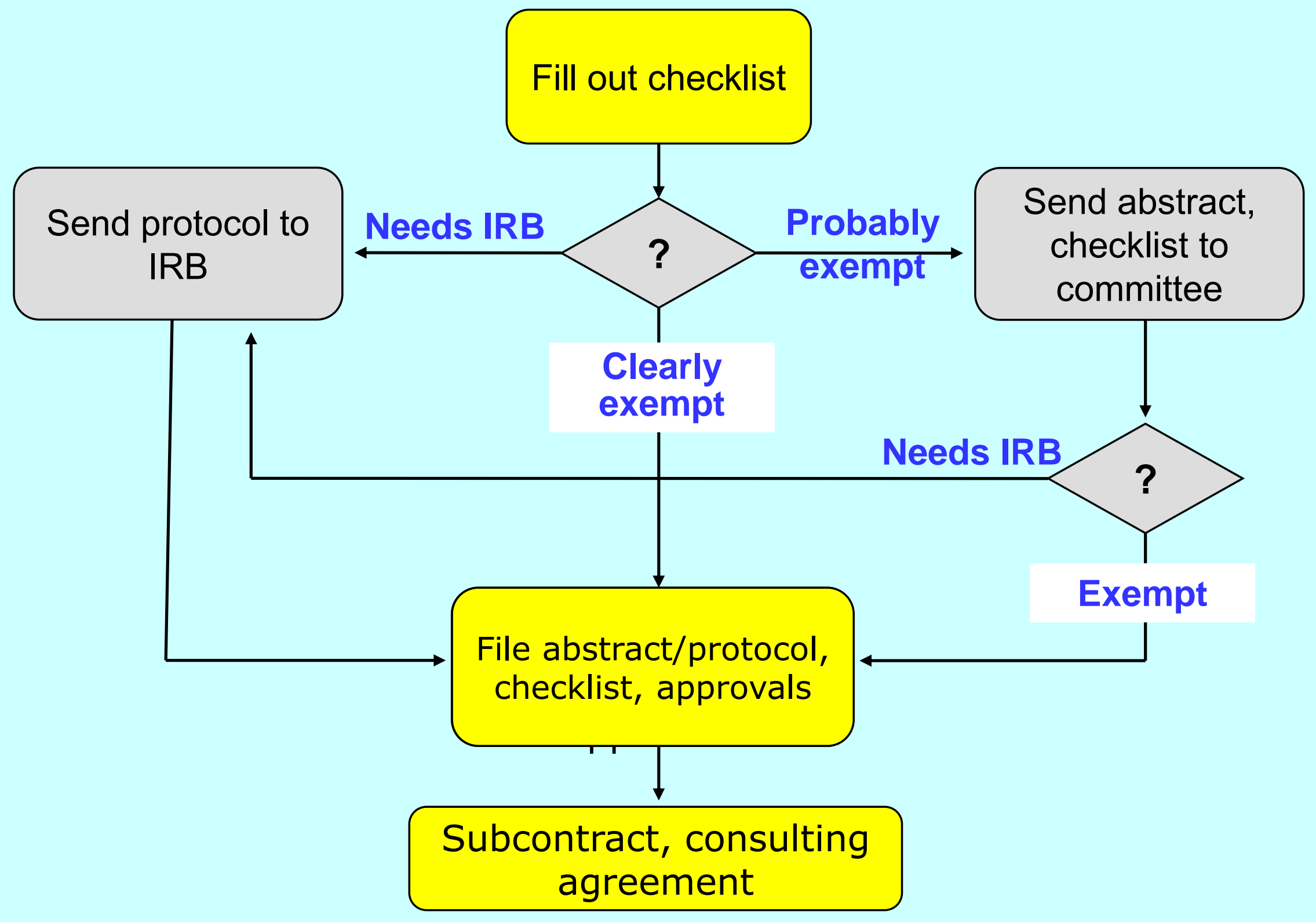




\section{Levels of IRB Oversight}

- Full review

- Exempt from review

- Work performed by consultants (e.g. market research companies) requires review 


\section{Full Review}

- Full IRB review: Collection and/or Analysis of

- Biological specimens

- Medical records

- Interviews with children

- Interviews placing subjects at risk of criminal or social liability

- Sensitive Information 


\section{Exempt From Review}

- Further analysis of surveys

- Studies using service statistics data

- Quality assurance activities

- Surveys/interviews not covered under full review (Still requires informed consent and data protection)

- Most OR exempt from review 


\section{Elements of Informed Consent}

- Research description

- Risks

- Benefits

- Alternatives

- Confidentiality

- Make sure data is stored according to ethical guidelines.

- Compensation

- Contacts

- Voluntary participation 


\section{For Free Research Ethics Courses}

- Family Health International. 2001. Research Ethics Training Curriculum, www.fhi.org/training

- CITI. 2004. IRB International Training, www.irbtraining.org (Available in Chinese, English, French, Spanish, Portuguese) 


\section{Session 13: Handout Research Ethics}

\section{Guide for Interpreting the Federal Policy for the Protection of Human Subjects}

For research involving human subjects, a large majority of Federal Agencies simultaneously published a regulation or "Common Rule" on June 18, 1991 to regulate the conduct or support of such research. The following Interpretive Guide to the Federal Policy for the Protection of Human Subjects or "Common Rule" was developed by a working group of individuals who attend the Human Subjects Research Subcommittee, Committee on Science, National Science and Technology Council. It does not necessarily represent the position of any of their respective agencies.

\section{How to Interpret the Federal Policy for the Protection of Human Subjects or "Common Rule" (Part A) 2/2/99}

This Interpretive Guide to the Federal Policy for the Protection of Human Subjects or "Common Rule" was developed by a working group of individuals who attend the Human Subjects Research Subcommittee, Committee on Science, National Science and Technology Council. The document does not necessarily represent the position of any of their respective agencies.

\section{Purpose}

The purpose of this document is to clarify and provide guidance on how to interpret selected aspects of the Federal Policy for the Protection of Human Subjects (Part A) sometimes called the Common Rule. The guidance is not intended to be exhaustive, but to help deal with a number of common concepts and issues often raised in the human subjects protection process. Thus it is intended to be used as a companion to the Common Rule itself. In addition, institutions must adhere to other laws and regulations applicable to their human subjects research including state law, foreign laws, and human subjects procedures of the Food and Drug Administration (FDA.)

\section{Empowerment, Flexibility and Discretion of Institutions and IRBs.}

Trust in the honest, conscientious judgment of the human beings who serve on IRBs is pivotal to the entire system of protection of research subjects. Indeed, the system recognizes that there is no simple formula to apply to ethical decisions, and instead it vests the major responsibility of ethical decision making with the IRB. IRB actions are to be based on ethical principles (such as outlined in the Belmont Report.) They should fully recognize that ethical decisions involve a balance among such principles (such as respect for persons, beneficence, and justice) along with the importance of the knowledge that may reasonably be expected to result from proposed research (the requirement for which is itself grounded in the principle of beneficence.) In order to carry out its mandate, Institutions and IRBs are empowered with very wide discretion within the bounds of the Common Rule. Recognizing the very wide range of situations under which research may occur, above all else, the IRB should strive to do "the right thing" as it sees it. The regulations allow considerable flexibility to serve that purpose.

Institutions, IRBs and investigators all have a serious role to play. In the interest of promoting human subjects protection, it is important for institutions and IRBs to take a facilitative, collegial and educational posture with respect to investigators rather than a burdensome adversarial one. The IRB should encourage investigators to embrace ethical behavior by acting to facilitate ethical 
research and not be seen as an obstacle to the conduct of research. To that end, institutions and IRBs should promote education outreach efforts, and are encouraged to use their broad discretion to adopt creative administrative and other means to reduce administrative burden and maximize attention to the most important ethical issues.

\section{What is Research Under the Common Rule?}

The Common Rule defines research as "... a systematic investigation including research development, testing and evaluation designed to develop or contribute to generalizable knowledge." Further, as described in the Belmont Report "...the term 'research' designates an activity designed to test an hypothesis, permit conclusions to be drawn, and thereby to develop or to contribute to generalizable knowledge.... Research is usually described in a formal protocol that sets forth an objective and a set of procedures to reach that objective."

Thus a key aspect of research is that there be a systematic design in advance, generally utilizing a scientific approach or protocol, for the definite purpose of contributing to generalizable knowledge. Research can include a wide variety of activities including: experiments, observational studies, surveys, tests, and recordings designed to contribute to generalizable knowledge. It generally does not include such operational activities as: medical care, quality assurance, quality improvement, certain aspects of public health practice such as routine outbreak investigations and disease monitoring, program evaluation, fiscal or program audits, journalism, history, biography, philosophy, "fact-finding" inquiries such as criminal, civil and congressional investigations, intelligence gathering, and simple data collection or data collection for other purposes. However, some of these activities may include or constitute research in the specific circumstance where there is clear advance intent to contribute to generalizable knowledge with a formal scientific protocol.

\section{Human Subject}

This means a living individual about whom an investigator obtains 1) data through intervention or interaction or 2) identifiable private information. Intervention includes physical procedures and manipulations of the subject or the subjects environment for research purposes and interaction includes communication between the investigator and the subject. Private information includes information about behavior in which an individual can reasonably expect that no observation is taking place, or information for specific purposes (such as a medical record) that individuals can reasonably expect will not be made public. Private information must also be individually identifiable (i.e. the subject's identity is or may be readily ascertained by the investigator or the subject's identity readily associated with the information.)

Thus, simple observational studies of public behavior (including television and internet chat rooms) do not involve human subjects as defined, because there is no intervention or interaction and the behavior is not private. Also, studies based on data collected for non-research purposes do not constitute human subjects research unless individual identity is readily identifiable. Examples include: programmatic data such as service statistics, school attendance data, crime statistics, election returns, vital statistics, and pathologic specimens collected for therapeutic purposes (where such information does not readily identify individuals.) A number of the specific exemptions in the Common Rule (see below) further address some of these and similar situations.

\section{Exemptions}

Survey and certain similar research - 101(b)(2). The Common Rule exempts such research except in situations where each of two things occurs: first the information would allow subjects to be identified (either directly or through identifiers linked to the subject) and second "any disclosure of the human subjects responses outside the research could reasonably place the 
subject at risk of criminal or civil liability or be damaging to the subjects' financial standing, employability or reputation." Thus, survey and similar research under formal human subjects protection is "covered" only when both privacy/confidentiality might be compromised through identification and the nature of the information disclosed is very sensitive. In determining whether there might be a reasonable risk or damage related to divulging the sensitive information etc., it is not enough that there be merely some hypothetically possible risk that can be construed. Rather the risks resulting from disclosure must be readily appreciable and significant.

Research involving the collection or study of existing data or specimens - 101(b)(4). "Existing" means existing at the time the research is conducted. Some Agencies interpret this to mean existing at the start of the research and some Agencies include as "existing" sources such as vital records routinely created on an ongoing basis without alteration, even though some may be created after the start of the research. This research is exempt if these sources are publicly available or if the information is recorded by the investigator in such a manner that subjects cannot be identified directly or through identifiers to the subjects. Thus the key point is how the data are recorded. The research would remain exempt if the investigator had access to identifiable information (such as medical records) but did not record identifiers. Moreover, consistent with the definition of human subject, identification need be readily ascertainable. Research would remain exempt for example if identity is linked only by legitimate encryption or other procedures that make it very difficult for investigators to identify individuals.

Public Benefit or Service Programs (101)(b)(5). This exemption to study, evaluate or otherwise examine public service or benefit programs is fairly broadly written. However, it is generally interpreted to be limited to research on the process or outcomes of service delivery (e.g. programmatic research or operations research.) DHHS, in fact interprets this exemption narrowly to apply primarily to entitlement and "entitlement-like" programs such as Social Security.

\section{Waiver or Alteration of Informed Consent}

Section 116 (d) provides conditions for waiving or altering the informed consent procedure for research involving no more than minimal risk. A key condition is that "The research could not be practicably carried out without the waiver or alteration." The determination that the research could not be practicably carried out is not a matter of mere inconvenience to the research process. Rather, there need be a plausible concern that either the conduct or the findings of the research might be adversely affected by the consent process. An adverse effect might include a substantial delay or increase in cost. Examples of situations where waiver or alteration of informed consent may often be justified are minimal risk (and non-exempt) social science methods involving deception; and surveys and cultural anthropology where implementation of all or part of the informed consent process might offend or raise unwarranted suspicions among respondents thereby adversely affecting the research. Certain medical record review research is another common example where consent may not be practicable. Section 117 (c) allows for waiver of a signed consent form under certain circumstances, but does not otherwise alter the consent requirements per se.

\section{Informed Consent to Promote Communication}

Recognizing that communication is an imperfect human process, in the interest of better human subjects protection, it is important to recognize the informed consent process as a process of communication and not just a legal requirement. The consent form should not be confused with the informed consent process. In the interest of good communication, the process should promote: simple understandable language; emphasis on the required and most important information, and avoidance of "information overload," without large amounts of additional information of marginal use to the consent process. The process should also promote good communication techniques such as active listening, individualizing and requesting restatement by the subject. 


\section{Minimal Risk}

As defined in the Common Rule this "... means that the probability and magnitude of the harm or discomfort anticipated in the research are not greater in and of themselves than those ordinarily encountered in daily life or during the performance of routine physical or psychological examinations or tests." More specifically it means the risks encountered inherent to the daily lives of the population or class of research subjects involved and the additional of risk added by the research. Thus, a treadmill test of low intensity might be minimal risk for the population in general, but more than minimal risk for research conducted with a group of cardiac patients. Likewise, measuring blood levels of a drug with serious side effects among a group of patients already receiving it for therapy might be considered minimal risk, whereas administering the same drug solely for research purposes and measuring it among the healthy population could be more than minimal risk. This standard should not be interpreted to mean that additional highly risky or potentially harmful interventions are considered minimal risk for certain severely ill patients simply because such patients are subject to such interventions as part of their treatment. Many nonexempt surveys may be considered minimal risk since they do not exceed the harm or discomfort of certain psychological examinations or tests or those ordinarily encountered in daily life.

\section{Expedited Review}

In order to qualify for expedited review, research must be 1) both on the list of expedited review procedures published in the Federal Register and be found by the reviewer to be of minimal risk, or 2) involve only minor changes in approved research. Expedited review per se does not mean any decrease in human subjects protection required in the conduct of the research itself.

\section{Timing of IRB Review in Relation to Funding}

Covered research may not be supported without certification that the research has been reviewed and approved by the IRB. The Common Rule itself does not actually require IRB approval prior to agency review and/or funding, but some Agencies may. In addition Sections 118 and 119 provide for activities funded without definite plans for human subjects research. In any case, IRB approval must precede the actual conduct of the covered human subjects research.

\section{Multiple Site Research}

Section 114 addresses cooperative research. Each institution is responsible for safeguarding subjects rights and following appropriate procedures. However, institutions may rely on the review of another qualified IRB. It is recognized that the types of research, the levels of risk and the kinds of sites where cooperative research takes place vary widely and the need for considerable adaptability is recognized. For example, the mere fact that research occurs at a certain place (such as a health department, school or supermarket) does not mean that "place" would be considered a research institution. If a site is only opening its doors to researchers or data abstractors, or is merely providing data, it is not considered a research institution. While it is not necessary that every site or every institution provide its own IRB review (an IRB may be "remote" from the site of the actual research,) it is important that the IRB review and oversight that is conducted is explicitly considered competent and cognizant of the conditions and situations in the sites under its purview. One specific mechanism is a cooperative amendment to assurances of institutions participating in cooperative research, which can be agreed to by those institutions, and approved by the sponsoring agency to document the terms of reliance on another institution's IRB.

\section{Continuing Review}

IRBs must conduct continuing review of covered research at least annually. IRBs have 
considerable latitude in what the review entails. The key concept is that the review be substantive and meaningful. In some cases it may involve a complete review of the entire protocol by the full IRB together with any additional changes, events and findings. It may also include observations of the research or the consent process. In other instances, IRBs may adopt more expeditious procedures, for example relying on findings of a principal reviewer or on research progress reports. The IRB may consider a biomedical or other intervention study closed when all active participation of the subjects has ended and the investigator is no longer accessing private identifiable information. Once a study is closed, it is a good idea to have reasonable ongoing procedures in place as appropriate and practicable, to protect confidentiality and to provide feedback of relevant emerging information to subjects.

\section{Promoting Ethical Behavior in Areas Exempt from the Common Rule}

Even though certain classes of research are exempt under the Common Rule, they should not be considered exempt from common ethical standards. For example, a certain survey may be exempt, but it is common courtesy and otherwise generally reasonable to ask permission and provide some simple information to respondents. Likewise, research on existing specimens might not record identifiers and thus be exempt, but researchers ought still to take care to protect individual privacy. The interest in promoting ethical behavior outside the common rule is not intended as a mandate for more structured procedures, but rather to advance a cultural norm of ethical behavior for research and non-research activities alike, to be exercised with discretion by institutions and individuals.

\section{Promoting More Active Oversight of Higher Risk Research}

As with any undertaking, a sense of priority is important in dealing with human subjects research and institutions are encouraged to exercise more active oversight beyond the minimum requirement of the Common Rule for certain higher risk research, as appropriate.

More active oversight could include such activities as special educational outreach to investigators and other appropriate stake holders, site visits and observations of research activities, research participant interviews as appropriate, ongoing IRB briefings of research progress, timely monitoring and evaluation of untoward events, and data monitoring and safety boards. 


\section{Session 14: Instructor's Guide \\ Exercises: Research Ethics}

\section{SESSION OBJECTIVES:}

- Reinforce participant knowledge of research ethics

\section{POINTS TO EMPHASIZE:}

- Be sure that participants understand the basics of research ethics - that the exercises are all completed satisfactorily

- Emphasize that the case studies in exercises 3 and 4 are typical of ethics issues encountered in OR studies

\section{SESSION METHOD:}

- Exercises 1 and 2 should be done in a large group. All groups should complete each case study. When completed, groups should present in front of all participants and facilitator should ask if any groups had other answers. These should be discussed.

\section{EXERCISES:}

DURATION: 2 hours

\section{Materials}

1. PowerPoint: "Research Ethics Exercises"

2. Handout: "Case Study 1: Respect for Persons"

3. Handout: "Case Study 2: Informed Consent"

4. Handout: "Case Study 3: Equity"

5. Handout: "Case Study 4: IRB Review" 


\section{Research Ethics}

\section{Exercises}




\section{Exercise 1: Ethical Principles}

1. Give 2 examples of vulnerable populations.

2. Describe contents of an informed consent form.

3. Can you pay participants in a research project?

4. You are going to analyze last year's data from medical records to determine age profile of clients. No names will be used in the report. Does this study need ethical review? 


\section{Exercise 2: Informed Consent}

1. How could you demonstrate that you received the informed consent of illiterate participants in a survey?

2. You hire a market research firm to carry out a research project. Are they exempt from obtaining informed consent?

3. Give examples of the information that must be contained in an informed consent form.

(P) Population Council FRONTIERS 


\section{Case Studies}

- Read each case study and answer the questions 


\section{Session 14: Case Studies Research Ethics}

\section{Case Study 1: Respect for Persons}

A local Ministry of Health has requested a prevalence/behavioral surveillance study for sexually transmitted infection (STI) among commercial sex workers. Participants in this study will be tested for 3 common STIs and participate in an interview. Participants will receive a card with a number linking them to their blood sample. Women who donate blood will have the option of presenting their card to get the results of the STI tests. Those with positive results for any of the 3 infections will be offered free treatment. In addition, all participants will receive a small gift in return for their participation

The target population consists of brothel-based sex workers who are strictly controlled by the brothel managers. Prior to initiating the research, the researcher meets with the brothel manager to ask permission to conduct the study. During the meeting, the manager states that all of the women working in the brothel will participate in the study.

\section{Questions:}

1. What steps can the research staff take to ensure that the informed consent is freely given by all participants?

2. If a woman chooses not to participate in the study, what can be done to protect her from retaliation?

3. If you believe that the women will not be able to give voluntary informed consent, what alternatives could you suggest to the Ministry of Health? 


\section{Case Study 2: Informed Consent}

A randomized placebo-controlled trial of a vaginal microbicide product is underway in a resource-poor country. The purpose of this trial is to look at the effectiveness of a topically applied microbicide on heterosexual acquisition of HIV. Half of the women enrolled will receive the test product and condoms and the other half will receive a placebo and condoms. Both the local ethics committee (EC) and sponsor's EC have approved this research and the consent process.

During a routine monitoring visit for this trial, the monitor observes the consent process for several study participants. The monitor finds that the study counselors administering the informed consent do not explain all of the information on the consent form as was planned at the staff training. In fact, most of the consent form is paraphrased and several essential elements are omitted. All participants sign the consent form

When the counselors are questioned about this, they state that the women at this site are not capable of understanding everything in the consent form, so the site counselors and the study investigator agreed on emphasizing only the most important aspects of the consent form.

The monitor speaks to the investigator about this issue. She is told that investigators are encouraged to review and modify consent forms as necessary to account for local conditions. The investigator feels that the study counselors were correctly following the informed consent process. The monitor reports her findings to the EC.

\section{Question:}

\section{In this case the ethics committee should:}

a). Recommend that the study be terminated.

b). Retrain the site investigator and the study staff in the informed consent process,

c). Rely on the site investigator's knowledge of the study population

d). No action. The site investigator has signed consent forms for each participant. 


\section{Case Study 3: Equity}

The Ministry of Health of the country of Mosquitia wishes to determine if households that pay a small amount for insecticide treated bed nets will be more likely to use the nets than households that receive them free of charge (Many in the Ministry believe that people who pay for a product are more likely to use it than people who receive it for free). A quasi-experiment is planned. Households in one health districts will be offered bed nets for the price of $\$ 1$ each. Households in a matched district will be offered free bed nets. Both districts are very poor. After six months, research staff will visit all households in each district to determine the number and percent of households that use the nets consistently and correctly. A group of citizens in the district where the ministry will charge for the bed nets claim that it is unethical to make them pay for the same product that others are receiving free of charge.

1. When should informed consent be obtained? When the nets are sold/given away, or during the survey?

2. Do you agree or disagree with the citizens who say the study is unethical?

3. Instead of doing the experiment in two poor districts would it be better to do the study by selecting a rich district to try the payment intervention and compare it to the poor district? 


\section{Case Study 4: IRB Review}

A German based social marketing program wishes to determine if a national mass media campaign in Botswana will increase drugstore sales of condoms. The dependent variable is the number of condoms sold before, during, and after the campaign. Data will be collected from routine drugstore inventory records maintained by the program.

1. Does this study need IRB review? Why or why not?

2. If IRB review is necessary, boards located in which country must review the proposal? 


\section{Session 15: Instructor's Guide \\ Preparing a Research Budget}

\section{SESSION OBJECTIVES:}

- To present the elements usually found in an operations research budget

POINTS TO EMPHASIZE:

- Give examples when defining direct and indirect costs

- Types of costs incurred in an OR budget

- Discuss the format and information of the budget in the handout

\section{SESSION METHOD:}

- Lecture/discussion

\section{EXERCISES:}

DURATION: 1 hour

\section{Materials}

1. PowerPoint presentation: "Preparing a Research Budget"

2. Handout: "Research Budget Model" 


\section{Preparing a Research Budget}




\section{First Factors to Consider in Preparing A Research Budget}

- Who is the payer?

- What will they pay for?

- What is the budget ceiling?

- What is your timeframe?

- Direct and Indirect Costs

- Remember you are ESTIMATING! 


\section{Types of Resources}

Depend on your proposed activities!

-What are your proposed activities?

-What resources are necessary to deliver the proposed activities?

- Direct and Indirect Costs

- Research Resources and Costs

- Intervention Resources and Costs 


\section{Types of Resources Resources and Costs}

- Researcher Time

- Training

- Resource Persons - Analysts

- Consultants

- Transport/Travel

- Forms (Copying and Printing)

- Telephone

- Internet

- Software 


\section{Types of Intervention Resources and Costs}

- Counselor Time

- Training

- Resource Persons

- Consultants

- Transport

- Forms (Copying and Printing)

- Medical Supplies

- Media Time 


\section{Budget Preparation}

- Develop a spreadsheet

- Identify activities

- What are your estimated research resources?

- What are your estimated intervention resources?

- Calculate indirect costs 


\section{Session 15: Handout Model OR Project Budget}

\section{Research Costs}

\section{A. Salaries}

1. One Research Director: 10 months@ $@ 1000$ per mo.

US Dollars

2. Four data collectors for 6 months@ $\$ 200$ per mo. each

10,000

3. One data entry clerk for 10 weeks@ \$50 per week

B. Materials

1. Printing 4000 data collection forms @ $\$ .10$ per form

400

2. Printing of 250 final reports @ $\$ 2.50$ per report

625

3. Office supplies

C. Transport

1. Car Rental 10 months @ $\$ 600$ per month

2. Gasoline 10 months @ \$150 per month

3. Four Data collectors bus fare for 6 months @ \$25 per mo. Each

D. Dissemination Costs

1. Venue Rental 2 meetings@\$200 per meeting

\section{Subtotal Research:}

$\$ 25,025$

\section{Intervention Costs:}

\section{A. Contraceptives}

1. Five thousand IUDs @ \$2 per IUD

B. Training:

1. Four IUD trainers for 2 weeks @ $\$ 700$ per week

Subtotal Intervention:

$\$ 15,600$

Subtotal Direct costs:

$\$ 40,625$

III. Indirect Costs $15 \%$ of Direct Costs:

$\$ 6094$

IV. Grand Total Direct Plus Indirect Costs: 


\section{Session 16: Instructor's Guide The Research Proposal}

\section{SESSION OBJECTIVES:}

- To prepare participants' to critically evaluate the quality of an OR proposal

\section{POINTS TO EMPHASIZE:}

- The proposal must be organized in a logical manner

- The session presents a formula for organizing the proposal in a logical manner

- Sections of the proposal can be used in writing subsequent reports on the study

- Different organizations request proposals in different formats, but the basic format in this session contains almost all the sections required by organizations such as WHO and the UN

- Review and discuss the handout "Suggested Proposal Outline" with participants

\section{SESSION METHOD:}

Lecture/discussion

\section{EXERCISES:}

DURATION: 1 hour

\section{Materials}

1. PowerPoint presentation: "The Research Proposal"

2. Handout: "Suggested Proposal Outline" 


\section{The Research Proposal}




\section{Why is the Research Proposal Important?}

- Mechanism for getting a research grant

- Blueprint for the study protocol

- Proposal information can be used in final report 


\section{Proposal Sections}

- Abstract/summary (used in final report)

- General introduction (used in final report)

- Justification of study (used in final report)

- Research objectives (used in final report)

- Methodology (used in final report)

- Dissemination plan

- Timeline

- Ethical issues (used in final report)

- Itemized budget

- Budget justification 


\section{Abstract}

- A miniature version of proposal

- One page or less

- Contains brief synopsis of introduction, research objectives, methods, utilization, duration, and budget sections 


\section{Introduction}

- General problem

- Specific problem in study country/program

- Justification for need of study

- Research objectives, contents 


\section{Methodology}

- Design and participants

- Assignment technique (if experiment)/proposed sample size

- Operationally defined variables

- Study procedure

- Measurement and analysis plan 


\section{Timeline}

- Start and end dates

- Total months

- Specific activities presented on grid in ordinal months 


\section{Ethical Issues: OR study}

- Risks and benefits

- Informed consent

- Confidentiality 


\section{Utilization}

-Who will utilize the data (departments, staff titles)?

- For what decision (be as specific as possible)?

- When must the decision be made?

- Who would provide resources for wider use of results? 


\section{Dissemination}

- Audiences

- Contents

- Techniques for reaching different audiences 


\section{Budget}

- Total budget

- Itemized budget

- Justification of major line items 


\section{Line Items of Budget}

- Personnel/research staff

- Intervention cost

- Data gathering costs

- Administration, communication, and logistics

- Dissemination 


\section{Session 16: Handout Operations Research Proposal Outline}

A. Abstract: Approximately 250 words. Sections include: Background, objective; methodology; duration of research (include preparation and data analysis) and budget.

B. Introduction:

1. Public health problem

2. Brief description of the agency and program which follows logically from the public health problem (e.g. "Charity International is attempting to address the above problems through a comprehensive program..." and introduces the program problem. Include any collaborating organizations (E. g. $\mathrm{MOH}$ )

3. Program problem

4. Solution that will be tested

5. Research objective

C. Methodology:

1. Independent variable: operational definition and a brief description of procedure for manipulating/implementing the independent variable (e.g. "HIV positives will be prescribed $X$ and will be visited to determine compliance with the treatment procedure every month..."

2. Dependent variable: operational definition and measurement; planned comparisons; data collection methods, and quality assurance

3. Design: Including brief discussion of why it was selected, unit of analysis, number of units, method of assignment

4. Monitoring implementation of the intervention

\section{Duration/Time line of activities}

E. Ethical Considerations

F. Utilization

G. Dissemination

H. Itemized Budget

I. Budget Justification

\section{J. Appendixes (e.g. informed consent form)}




\section{Session 17: Instructor's Guide Exercises: OR Proposal Critique}

\section{SESSION OBJECTIVES:}

- To strengthen participant's proposal evaluation skills

\section{POINTS TO EMPHASIZE:}

- Participants should read both proposals.

- Participants should read both the handout from session 14, "Suggested Operations Research Proposal Outline" and the handout out from the current session "Criteria for OR Proposal Critique" prior to reading the proposals.

- Each group will decide if the proposal should be funded, rejected or returned for major revision.

- Emphasize that there is no "correct" or "incorrect" decision.

- Each group will rate the proposal in terms of organization, completeness, importance of the problem and adequacy of the research approach.

- Some text in the methodology section of the Ghana proposal has been cut for the sake of brevity.

\section{SESSION METHOD:}

- Participants should critique the proposal in small groups.

\section{EXERCISES:}

See above

DURATION: $2 \frac{1}{2}$ hours

\section{Materials}

1. Word document: Handout " Criteria OR Proposal Critique"

2. Word document Handout (Proposal) "Systematic Screening to Meet Unmet Need by Integrating Reproductive Health Services"

3. Word document Handout (Proposal) "Acceptability, Feasibility and Affordability of the WHO Goal Oriented ANC Package in Ghana" 


\section{Session 17: Exercise 1 OR Proposal Critique}

Instructions: Two actually submitted OR proposals will be distributed to participants for critiquing. Form four groups. Each member of the group must read every proposal. Groups will be randomly assigned to critique one of the two proposals and tell the rest of the participants if you recommend:

1. Funding the proposal or funding after minor revision

2. Funding only after major revision

3. Not funding the proposal

When you present your critique, begin with a brief synopsis of the proposal.

Remaining groups will comment on the critique.

Proposal reviewers must give reasons for their recommendations. Having an explicit set of criteria for making your recommendations helps you to consider important aspects of each proposal and apply the same standards to every proposal. Below find criteria you should use in judging each proposal. In addition to the listed criteria, you should use some of your own criteria that can vary from proposal to proposal. The group should state any additional judgment criteria during their presentation.

\section{Some Standard Criteria:}

1. Does the proposal include all necessary sections?

2. Is the proposed research OR as defined in this workshop?

3. Is the proposal clearly written? Can the reader understand what is being proposed?

4. Is the research ethical?

5. Do you agree that the program problem is important?

6. Is there an intervention? Is it strong enough to improve the problem?

7. Is the solution sustainable? Likely to be scaled-up?

8. Is the methodology adequate to answer the research question?

9. Is the study too ambitious? Not ambitious enough?

10. Are the persons/organizations who will utilize the research identified?

11. Is there a concrete statement of how the results will be utilized?

12. Are the budget and duration of the study reasonable? 


\section{RESEARCH PROPOSAL 1}

TITLE:

LOCATION:

DURATION:

TOTAL COST:
Systematic Screening to Meet Unmet Need

by Integrating Reproductive Health Services

India

Nine Months

(April 1 - December 31, 2004)

US\$ 37,800 


\section{SUMMARY}

The objective of this study is to test a selective screening tool to determine if the use of the tool increases the ratios of services, future appointments and referrals among women 15 - 49, in Baroda, Gujarat, India. The study will use an experimental pre-posttest design with random assignment of six matched clinics to experimental and control groups. The unit of analysis will be the individual visit. A total of approximately 1,800 observations will be obtained during the four-month (two months before the intervention and two months after) period of field research. If the intervention is successful in increasing the ratio of services to visits, it will be introduced into other Municipal Clinics in Baroda and perhaps in Gujarat state clinics as well. Total duration of the study including design, field research and dissemination phases will be nine months. 


\section{BACKGROUND}

In India, many public health program clients, especially women with young children, have multiple needs for preventive and curative reproductive health services. Generally, health care personnel provide only the service requested by the clients and do not try to identify their other reproductive health needs. Clients may be unaware of their other reproductive health needs, or may be unaware that the additional services they need are available at the clinic. In any case, the user leaves the facility with unmet reproductive health needs and the service provider misses an opportunity to render those services. Integration, defined as the proactive provision of services by providers, may increase the number of reproductive health services obtained by women, but, in India, there is little proactive behavior by providers and a corresponding lack of integration.

One solution to the problem of lack of integration is to identify the client's needs and desire for reproductive health services when she first arrives the health facility for a visit, and to provide those services, either during the same visit, at a scheduled revisit, or through referral to another facility.

The present proposal is to conduct a study to test the feasibility and usefulness of introducing a systematic screening tool to increase the provision of multiple reproductive health services during the same client visit, appointments for future visits to the same facility, and referrals to other facilities. This intervention has been successfully tested in Bangladesh, Guatemala, Mexico and Peru.

\section{OBJECTIVE OF THE STUDY}

The overall goal of this study is to improve women's reproductive health by providing an integrated reproductive health services when they visit public health clinics in the city of Baroda. Specific study objectives are to conduct an experiment to:

- Increase the number of services provided per client visit

- Increase the number of appointments and referrals per client visit

\section{Hypotheses:}

Women receiving systematic reproductive health and maternal and child health services will receive more services per visit than women receiving standard screening procedures now used in Baroda.

\section{METHODOLOGY}

\section{Program Intervention}

The intervention will include:

1. Applying the Screening Instrument o identify the reproductive health needs of women of reproductive age (15-49), seeking care at a facility for themselves or their children less than 5 years of age

2. Offering the identified needed services during the same visit

3. Offering a future appointment at the same center or referral to another facility if the identified needs cannot be provided at the current visit or facility 


\section{Location of the Study}

The study will be carried out in the Municipal Corporation Health Clinics of Baroda in the state of Gujarat. The Municipal Corporation runs 11 Urban Health Posts (UHPs) and 2 subcenters located in low-income residential areas. These clinics provide maternal and child health, and family planning services, beside general curative services. Seven UHPs are fully developed clinics staffed with a lady medical officer, one lady health visitor, four auxiliary nurse midwives and one clerk. These centres provide comprehensive maternal and child health, and reproductive health care including treatment of STIs based on the syndromic approach. The clinics do not have laboratories and all cases requiring testing are referred to Baroda hospitals.

Usually 8-10 women of reproductive age attend the clinic daily for maternal and child health, and family planning services. High demand preventive care services such as immunization and antenatal care are offered once a week, and usually attended by 50-60 women. High demand services are also available daily, at client request.

The project will begin with a seminar for Municipal Corporation authorities and relevant health center directors in Baroda.

\section{Screening}

The services that we will screen clients for include family planning, Pap smears, well baby visits, vaccination, and other services requested by the Baroda Municipal Corporation.

In the experimental clinics, the intervention will use a Screening Instrument (SI). The SI will be a brief form that the person registering the client at the facility will use to identify services that a client may need. The SI will: (1) describe the services the client came for; (2) assess additional service needs; and (3) record services, appointments and referrals provided. The SI is shown in appendix A.

In the control clinics, and in the experimental clinics prior to the intervention, only the services requested and provided will be recorded (it is not ethical to screen without providing services) by interviewers. The exit interview form is shown in appendix B.

Since there is no pre-service registration system in the UHPs, and clients go directly to available service providers, the service provider will do all screening. The screening instrument will be translated into the local language and pre-tested before introduction. The interviewers used to collect the pre-test data will ask all clients entering the experimental clinics to give their informed consent to participate in the study. If consent is given, the interviewer will give the client a blank screening form to take to the provider, and will ask the client to return the form when her visit is completed. If the client wants to receive any of the identified services, the provider will mark the requested service and outcome of the consultation on the screening form.

All intervention group providers will be trained in screening. The daylong training will cover the use of the form and the advantages of the intervention for the clinic, health system and clients. The training will also include role-plays and supervised screening. To familiarize administrative staff with the intervention, a half-day orientation meeting will be organized in the intervention centers. 
A Baroda-based consultant will be hired for four months to supervise all clinic-based activities. The consultant will be either from the local Population Research Center, University of Baroda or the Municipal Corporation. The responsibilities of the consultant will include:

1. Providing assistance in organizing seminars/training

2. Supervising the screening work and proper completion of the screening forms

3. Arranging coding and data entry of exit interviews

A Population Council program officer will also supervise activities. The program officer will make weekly visits to intervention and control clinics during the first month of the before period. One visit per month will be made thereafter. Weekly visits will be made to the intervention group during the first month following introduction of the intervention, and two visits will be made during the second month. The consultant and Population Council staff will ensure that forms are correctly filled out; clients' dignity, auditory privacy and confidentiality maintained; and consent given prior to screening.

\section{Study Design}

The independent variable will be the Systematic Screening System described above. The dependent variables will include services per visit, appointments per visit and referrals per visit. The study will be a true experiment with a pre- and post-test design with control group as represented below:

Intervention: $\quad \mathrm{O}_{1} \quad \mathrm{X} \quad \mathrm{O}_{2}$

RA

Control: $\quad \mathrm{O}_{3} \quad \mathrm{O}_{4}$

4 months

Where:

$\mathrm{O}_{1} \& \mathrm{O}_{3}=$ Observation of the number of services, appointments and referrals per visit provided for two months before implementation of intervention in experimental and control clinics

$\mathrm{X}=\quad$ Introduction of Standard Screening Instrument in experimental clinics

$\mathrm{O}_{2} \& \mathrm{O}_{4}=$ Observation of the number of services provided to clients in experimental and control clinics for two months after implementation of intervention

$\mathrm{RA}=\quad$ Random Assignment

Only completely staffed and equipped UHPs will be included in the study. Out of seven eligible UHPs, six will be randomly selected and matched on client volume. Four clinics will be randomly assigned to the experimental, and two to the control group. The client visit will be the unit of analysis. None of the clinics are utilized to full capacity. There are no restrictions on the number of services that can be received during one visit. 
All women of reproductive age who visit intervention clinics for a two-month period before the introduction of the instrument will be interviewed, and after the introduction of the intervention they will be screened. In control clinics, clients will continue to conduct client exit interviews on services requested and provided during the entire fourmonth study periods. Duration of the data collection period will be four months (two before and after the intervention) to reduce the possibility of bias associated with very short time periods. It is expected that about 300 observations will be obtained from each clinic both before and after the intervention for a total of approximately 1800 observations.

Form B, administered as an exit interview, will be the source of all control group data, and pre-test experimental group data. The Screening Instrument (SI) will be the source of post-test experimental group data. Form B may also be used on a random basis in the experimental group during exit interviews intended to monitor provider compliance and data reliability.

Continuous data entry will be used during the study period. The analysis of data for the experiment consists of comparing the net change in number of services received per client visit in control and experimental clinics prior to intervention and after the intervention. The t-test will be used to compare pre- post-test changes in experimental and control group means.

\section{ETHICAL ISSUES}

\section{DISSEMINATION AND UTILIZATION}

Prior to testing the intervention, staff will discuss scaling-up needs with Baroda Municipal Authorities, and will help them to obtain the necessary resources if the intervention is successful. If successful, the possibility of adopting the intervention will also be discussed with State health authorities.

FRONTIERS staff will document the process and findings of the program intervention in a final report. Suitable management summaries and briefs will be prepared and widely circulated. The project will conclude with a dissemination seminar to share experiences with the different stakeholders including officials of different municipal corporations in the State, the State and Regional Health Directors, officials of the Ministry of Heath, NGOs and donor agencies. If the intervention is successful, a blueprint for scaling-up the intervention will be developed.

\section{TIME SCHEDULE}

The study will be completed in nine months, as shown in the chart below.

\begin{tabular}{|c|c|c|c|c|c|c|c|c|c|}
\hline \multirow{2}{*}{ Activities } & \multicolumn{8}{|l|}{2004} & \multirow[b]{2}{*}{$\begin{array}{l}\text { Month } \\
9 \\
\end{array}$} \\
\hline & $\begin{array}{l}\text { Month } \\
1\end{array}$ & $\begin{array}{l}\text { Month } \\
2 \\
\end{array}$ & $\begin{array}{l}\text { Month } \\
\mathbf{3}\end{array}$ & $\begin{array}{l}\text { Month } \\
4 \\
\end{array}$ & $\begin{array}{l}\text { Month } \\
5 \\
\end{array}$ & $\begin{array}{l}\text { Month } \\
6 \\
\end{array}$ & \begin{tabular}{|l|} 
Month \\
7 \\
\end{tabular} & \begin{tabular}{|l|} 
Month \\
8 \\
\end{tabular} & \\
\hline Planning and preparation & & & & & & & & & \\
\hline Selection of clinics & & & & & & & & & \\
\hline Translation of Screening form & & & & & & & & & \\
\hline Pre-test of screening form & & & & & & & & & \\
\hline
\end{tabular}




\begin{tabular}{|l|l|l|l|l|l|l|l|l|l|}
\hline Before intervention observations & & & & & & & & & \\
\hline Training of screeners & & & & & & & & & \\
\hline Orientation of clinic staff & & & & & & & & & \\
\hline Intervention phase & & & & & & & & & \\
\hline After intervention observations & & & & & & & & & \\
\hline Data entry, cleaning and validation & & & & & & & & & \\
\hline Analysis and report writing & & & & & & & & & \\
\hline Dissemination & & & & & & & & & \\
\hline
\end{tabular}

\section{BUDGET}

The total cost of the study will be US\$ 37,800 Itemized costs are given below

\begin{tabular}{|l|l|}
\hline Line Item & US\$) \\
\hline Personnel & \\
\hline Program/Research officer (100\% of time) 8 months & 16,000 \\
\hline Local Consultant to assist in the study (person for 4 months) & 2,000 \\
\hline 6 data collection staff x \$200 per month x 4 months & 4,800 \\
\hline Sub-total & $\mathbf{2 2 , 8 0 0}$ \\
\hline Cost of intervention and data collection & \\
\hline Cost of data collection including local travel cost of consultant & 500 \\
\hline Printing of screening form and office supply in Baroda & 500 \\
\hline Training of Screeners and orientation meeting of clinic staff in 4 clinics & 1,500 \\
\hline Sub-total & $\mathbf{2 , 5 0 0}$ \\
\hline Data analysis & \\
\hline Data entry, cleaning and validation, and analysis & 1,000 \\
\hline Sub-total & $\mathbf{1 , 0 0 0}$ \\
\hline Travel and accommodation at Baroda & 6,000 \\
\hline Sub-total & $\mathbf{6 , 0 0 0}$ \\
\hline Report preparation and dissemination of results & \\
\hline Final report, OR summary & 2,000 \\
\hline Dissemination meetings (at least 2 meetings) & 3,500 \\
\hline Sub-total & $\mathbf{5 , 5 0 0}$ \\
\hline Grand Total & $\mathbf{3 7 , 8 0 0}$ \\
\hline
\end{tabular}




\section{Project Proposal 2}

Project Title:

Acceptability, feasibility and affordability of the WHO Goaloriented ANC package in Ghana

Location:

Greater Accra \& Central Regions

Duration:

September 1, 2004 - May 30, 2005

Budget:

US $\$ 66,378$ 


\section{Problem Statement}

The proportion of women in Ghana who give birth with the assistance of a skilled birth attendant, a measure to reduce the risk of maternal morbidity and mortality, is rather low. Less than half ( 47 percent) of the births in Ghana are delivered by a health professional (preliminary GDHS results 2003). Also, Antenatal Care (ANC) services that are important in monitoring the progress of a pregnancy, identifying complications, referring mothers for specialized care at an appropriate time for intervention are not fully utilized by most women. A relatively substantial proportion of pregnant women are likely to wait until the second trimester (36 percent) and the third trimester, when it is too late to take potential preventive measures for some complications such as anemia. By the start of the sixth month of pregnancy, 14 percent of Ghanaian women have not made a single ANC visit. The median duration of gestation at which the first ANC visit is made is 4.3 months. The delayed use of services makes it difficult for the optimum benefits of ANC to be realized. Worse still, an estimated 10 percent of the women do not make a single ANC visit (GDHS 1998).

Problems of availability, accessibility, coverage and quality of care limit the gains of ANC services. Overall, quality of ANC services is rather poor. For instance, the GSPA survey 2002 found that:

1. Only 6 percent of the facilities offering ANC services have all the essential medicines to manage complications of pregnancies ${ }^{1}$;

2. Tests for anemia and protein were only available in 57 percent and 62 percent of the facilities, respectively;

3. Only half of the facilities have all essential equipment and supplies for ANC including blood pressure apparatus, fetoscope, iron and folic acid tablets and TT.

4. Only 36 percent of the facilities had essential items to offer quality counseling, 24 percent had essential items to prevent infections and 11 percent had all essential items for quality physical examination;

5. Routine history taking from clients was not comprehensive - some first visit clients were not asked about their age, date of last menstrual period, any prior pregnancy, and medicines being taken;

6. Identification of risk signs and symptoms was inadequate - only 29 percent of clients were asked about vaginal bleeding, 53 percent of women who were at least 5 months pregnant were asked about fetal movement and only 22 percent of the clients were subjected to all relevant components of pregnancy monitoring;

7. Tetanus toxoid was given or prescribed to 51 percent of first visit clients and to 34 percent of follow-up clients, while anti-malarials were given to 47 percent and 34 percent of first-visit and follow-up clients, respectively. Preventive screening for syphilis was done in less than 5 percent of the ANC clients;

8. Clients were not properly counseled to promote healthy outcomes - among women attending ANC for the first time, only 20 percent were counseled about exclusive breast feeding. Discussion of the progress of the pregnancy and delivery plans was observed in one-third of the interactions. Risk symptoms - vaginal bleeding, fever, short breath, swelling of hands and face, headache, or blurred vision - were discussed with only 27

\footnotetext{
${ }^{1}$ An antibiotic for ANC and PNC infections (amoxycillin or contrimazodale), deworming medicine (metromidazole, nystalin), an anti-malarial, and at least one medication for treating trichomoniasis, gonorrhea, chlamydia, syphilis.
} 
percent of the clients. Use of family planning postpartum was hardly mentioned - it was only observed in 19 percent of the interactions. These issues were also rarely discussed during subsequent visits.

Thus, even when pregnant women make an ANC visit they are likely to receive poor quality services that are not comprehensive. Moreover, the "assembly line" approach to delivery of ANC services practiced by ANC service delivery points does not encourage proper monitoring or follow-up and/or continuity in ANC service utilization.

\section{Possible Solutions - Refocusing ANC}

In order to enhance integration, continuity and quality of ANC services, the Government of Ghana (GOG) has exempted fees for four visits for women attending ANC and also adapted the WHO goal-oriented ANC package that encourages four ANC visits and individualized care. The specific aims of focused ANC in Ghana are to:

- Promote and maintain the physical, mental and social health of mother and baby by providing education to the pregnant mother and her family on nutrition, rest, personal hygiene, family planning, immunization, danger signs, RTI including STI/HIV/AIDS, birth preparedness and complication readiness;

- Detect and treat complications arising during pregnancy, whether medical, surgical or obstetrical;

- Ensure delivery of a full term healthy baby with minimal stress or injury to mother or baby;

- Help prepare the mother to breastfeed successfully, experience a normal puerperium and take good care of the child physically, psychologically and socially; and

- Prevent mother-to-child transmission of HIV/AIDS (GHS 2003).

In view of this, the Ghana Health Service (GHS) has designed new National Reproductive Health Services Policy and Standards that place emphasis on refocusing antenatal care (WHO ANC package). Unlike previous guidelines that expected women to make $12-13$ ANC visits during pregnancy, the current policy recommends that a healthy pregnant woman should have a maximum of four comprehensive personalized antenatal visits during pregnancy and be offered better quality and more 'focused' services relevant for each visit. According to the policy, ANC services should generally consist of the following activities:

- Monitoring of normal pregnancy

- Identification of complications of pregnancy

- Etc.

A major concern, however, is whether the Ghana health care system can cope with the implementation of the focused ANC package. There is widespread evidence that the health systems in sub-Saharan Africa are incapable of mounting effective health programs or even ameliorating them because of limited resources, supplies, poor infrastructure and shortage in trained personnel.

In Ghana, GHS has provided an enabling policy environment for adoption of the WHO goal oriented ANC package. The major limitations, however, are that the updated policies are not widely disseminated, revision of the service protocol is yet to happen, and only regional resource persons (trainers) have been trained in focused ANC so far. 
Since Ghana adopted the WHO goal-oriented approach and revised its policy and guidelines, little is known about how changes in ANC have been stimulated, its acceptability among service providers and clients, the content of ANC services at the clinic level, the process and feasibility of introducing focused ANC at different service delivery points, the variations in implementation of the package and how services get utilized over time and the sustainability of the approach. Even less is known about the cost of introducing focused ANC at different service delivery levels, affordability of the package, community awareness of focused ANC and whether utilization patterns for ANC have been influenced as such. This study proposes to assess the actual content, coverage, feasibility, acceptability and sustainability of focused ANC in Ghana. Barriers and constraints at system, programmatic and demand levels will also be assessed.

Specifically the study will address the following key research questions:

1. What contextual and process issues are influencing the feasibility and acceptability of the focused ANC package?

2. Is focused ANC acceptable to clients and providers?

3. What is the actual content and coverage of focused ANC and are different components being provided as a package at the service delivery level?

4. What effect does focused ANC have on quality of care offered to pregnant women under the focused ANC package?

5. Can public health facilities afford the additional costs associated with the introduction of focused ANC?

6. Can the health care system sustainably deliver a focused ANC package?

\section{Overall Goal}

The overall objective of the study is to assess the Ghana Health Service's (GHS) capacity to sustainably adapt focused ANC at the service delivery level and examine the extent to which adaptation of the package has increased coverage and quality of key ANC services and overall quality of care received by pregnant women.

\section{Intermediate Results}

Ministry of Health: The study will contribute to the goal of the Safe Motherhood programme "to improve women's health in general and specifically to contribute to the reduction in maternal and infant morbidity and mortality". The study also contributes to strategic objectives of the Second Programme of Work (2002 - 2006), "to improve quality of health delivery, to increase access to health services and improve efficiency of health service delivery."

\section{Operational Definitions}

\section{Feasibility}

The ability of the service delivery system to offer focused ANC continuously to clients over time. This will be quantitatively and qualitatively measured through facility assessment, key informant interviews, and focus group discussions with health development partners, program managers and providers.

Coverage of focused ANC 
Data will be collected through key informant interviews, provider interviews and maternal health cards review.

\section{Quality of care received by pregnant women}

\section{Provider capability to offer focused ANC}

\section{Awareness and acceptability of focused ANC}

1. Proportion of pregnant women who are aware of focused ANC in terms of what is offered at each visit.

2. Proportion of pregnant women whose ANC utilization behavior has changed, measured as: a) Pregnant women who make the first ANC visit at < 16 weeks; b) pregnant women who make the second ANC visit between 24-28 weeks; and c) pregnant women who make third visit during $32-36$ weeks.

3. Proportion of providers indicating approval and satisfaction with offering focused ANC.

Data will be collected through client exit interviews, a review of client ANC cards and provider interviews.Clinic performance

1. Competence of providers: the proportion of providers who correctly provide ANC care according focused ANC guidelines. Data will be collected through observations of client-provider interactions and provider interviews.

2. Quality of care

3. Satisfaction with services:

- Proportion of women satisfied with the various aspects of services provided; and

- Proportion of women who would recommend the clinic to others; and

1. Financial and non-financial resources of focused ANC

- Percent of district budget spent on RH services and/or ANC;

- Percent of facilities with adequate staff

- Proportion of clinics with minimum equipment and supplies to offer different components of focused ANC;

- Proportion of clinics with appropriate infrastructure to offer focused ANC;

- Proportion of clinics with reference manuals, registers, forms and revised ANC cards;

2. Issues about the context, process and actors that have influenced the introduction of focused ANC

Data will be collected through facility assessment, desk and stakeholders appraisal, and focused group discussions with service providers and consumers.Clinic performance

4. Competence of providers: the proportion of providers who correctly provide ANC care according focused ANC guidelines. Data will be collected through observations of client-provider interactions and provider interviews.

5. Quality of care

6. Satisfaction with services:

- Proportion of women satisfied with the various aspects of services provided; and

- Proportion of women who would recommend the clinic to others; and 
1. Clinic income versus costs associated with implementation of focused ANC;

2. Cost recovery levels of clinics (incomes versus expenditures);

3. Facility level financing by source; and

4. Incremental cost per year for introducing focused ANC package.

\section{Methodology}

\section{Study design}

To examine barriers and constraints to changing ANC services and health systems issues limiting their coverage and sustainability, the study will use an integrated case study design, involving a policy, situation, and cost analysis ANC. The situation analysis will respond to specific objectives $2,3,4,5$, and 9; the policy analysis will address specific objectives $1,4,5$, 6 and 9; while the costing analysis will respond to specific objectives 7 and 8 . The study will be conducted at the national, regional and district levels, covering two regions - Greater Accra and Central. $^{2}$ Greater Accra is where some of the first initiatives to introduce focused ANC started; while Central region focused ANC has only been partially introduced.The regions have been selected in consultation with the $\mathrm{RCH}$ Unit for purposes of giving a wider perspective on regional as well as district level factors.

\section{1) Policy analysis}

A key question in this study is how did GHS approach stimulating changes in ANC, and how far has it been able to achieve its goals at both policy and implementation levels? Two critical steps in this analysis will involve first an examination of the content of the national health policy and the reproductive health policy, and secondly, an assessment of the context, actors and process.

\section{Data collection and analysis}

\section{Desk appraisal}

A review of the current National Reproductive Health Service Policy and Standards will be undertaken to determine the content and the extent to which they facilitate or influence the provision of focused ANC at the service delivery levels. In addition, district health plans; annual and quarterly reports will also be reviewed for their intentions to translate policy into actual activities for focused ANC.

\section{Stakeholder appraisal}

A stakeholder appraisal will be applied, relying on qualitative approaches of data collection.

a) Key informant interviews at national and district levels:

Interviews will focus on:

\section{Contextual issues:}

2. Issues about the actors: What has been the influence of different actors on the implementation of the focused ANC package? Who were the main instigators of the change - internal policy-makers, external advisors, regional and district program managers? In particular, what role has WHO (local and global) played in influencing the government to embrace focused ANC as a national policy or strategy? 
Issues about the content: What is the content of ANC at the service delivery level? D

Process issues: How was the focused ANC package introduced and why?

\section{Methods}

- b) Focus Group Discussions with service providers and consumers: Focus group discussions (FGDs) will be used to gain a detailed understanding of the process of implementing focused ANC, its acceptability and feasibility among providers and consumers.

\section{Data management and analysis}

\section{2) Situation Analysis}

Data collection will include interviews with service providers, client exit interviews, clientprovider observations and review of ANC cards to measure coverage, availability, clinic performance, quality of care, awareness and acceptability of focused ANC.

Since the goal-oriented package for ANC has been partially introduced in Ghana, the study will apply a comparative design (see diagram below) using two groups of clinics; one where focused ANC $\left(0_{1}\right)$ has been introduced and another without focused ANC $\left(0_{2}\right)$. The clinics in group $\left(\left(0_{1}\right)\right.$ will be selected from Greater Accra and while clinics in group $\left(0_{2}\right)$ will be selected from the Central regions. Care will be taken in the analysis to control for locations of the clinics.

\begin{tabular}{llc} 
& \multicolumn{2}{c}{ Time } \\
\cline { 2 - 3 } Clinics with focused ANC & $\mathrm{X}_{1}$ & $0_{1}$ \\
Clinics without focused ANC & $\mathrm{X}_{2}$ & $0_{2}$
\end{tabular}

Where:
$\mathrm{X}_{1}$ :
Focused ANC package introduced
$\mathrm{X}_{2}$
Existing package of ANC
$0_{1} \&: 0_{2}$
Comparative measurements of:
- Coverage and availability
- Quality of Care received by pregnant women
- Clinic performance (provider competence, quality of care and satisfaction with services)
- Awareness and acceptability
Random process not applied in selection of the two regions and/or the clinics..

The analysis will cover seven SDPs purposively selected from each region. The SDP will be identified in consultation with the Regional and District Directors of Health services. 


\section{Data collection and analysis}

Facility assessment:

Provider interviews:

Structured observations of client provider interactions:

Client exit interviews:

Review of client's maternal health cards:

Patient flow analysis

\section{3) Cost analysis}

\section{Protection of Research Subjects}

Risks and benefits: Study participants will not be required to undergo any physically invasive procedures beyond those mandated by national norms for their antenatal care, i.e. a physical exam, and collecting blood and urine. The ANC package and clinic procedures to be received by the clients are the ones specified under by the focused ANC Guidelines. This study will be purely evaluative; no intervention is proposed.

\section{Dissemination and results utilization}

The study is expected to build on an interactive process with a range of stakeholders. As such, the study will stimulate debate about the acceptability and sustainability of focused ANC in Ghana, and identify the gap between policy recommendations and actual ANC service delivery and possible solutions to bridge this gap.

On completion of the study, a two-day data interpretation workshop will be held with the project partners (Noguchi Memorial Institute for Medical Research (NMIMR), Population Council, Reproductive and Child Health Unit, Malaria Control Program, Regional Directors of Health Services for Greater Accra and Central Regions and other selected stakeholders), and the Community-based Health Planning and Service (CHPS) initiative to interpret the results and draw out desirable inferences that will strengthen the implementation of focused ANC.

The RCH Unit has expressed interest in being able to clearly and reliably demonstrate the progress being realized in the implementation of the focused ANC in order to rationally plan and manage activities, but also be able to use evidence to advocate for the package. This study will generate systematic information on how the implementation of focused ANC is functioning, highlighting strengths and weaknesses and particularly documenting whether existing conditions and capacity support the successful implementation of the strategy. It is expected therefore, that the MOH, GHS and its development partners, regions and districts will find resources and commitment to base policy and program decision on the results of the study. 
It is also expected that information generated by the study will be useful in informing decisions on how to organize and manage focused ANC at the service delivery level in order to sufficiently sustain the package as well as policy outcomes. Thus, results of the study will be disseminated to program managers and service delivery providers in the two study regions for them to include recommended activities in their work plans.

A summary of the key study findings and their implications for ANC service delivery will also be circulated ahead of the Health Sector Joint Review Mission ${ }^{3}$, as way of lobbying for increased support for focused ANC.

\section{Study Schedule}

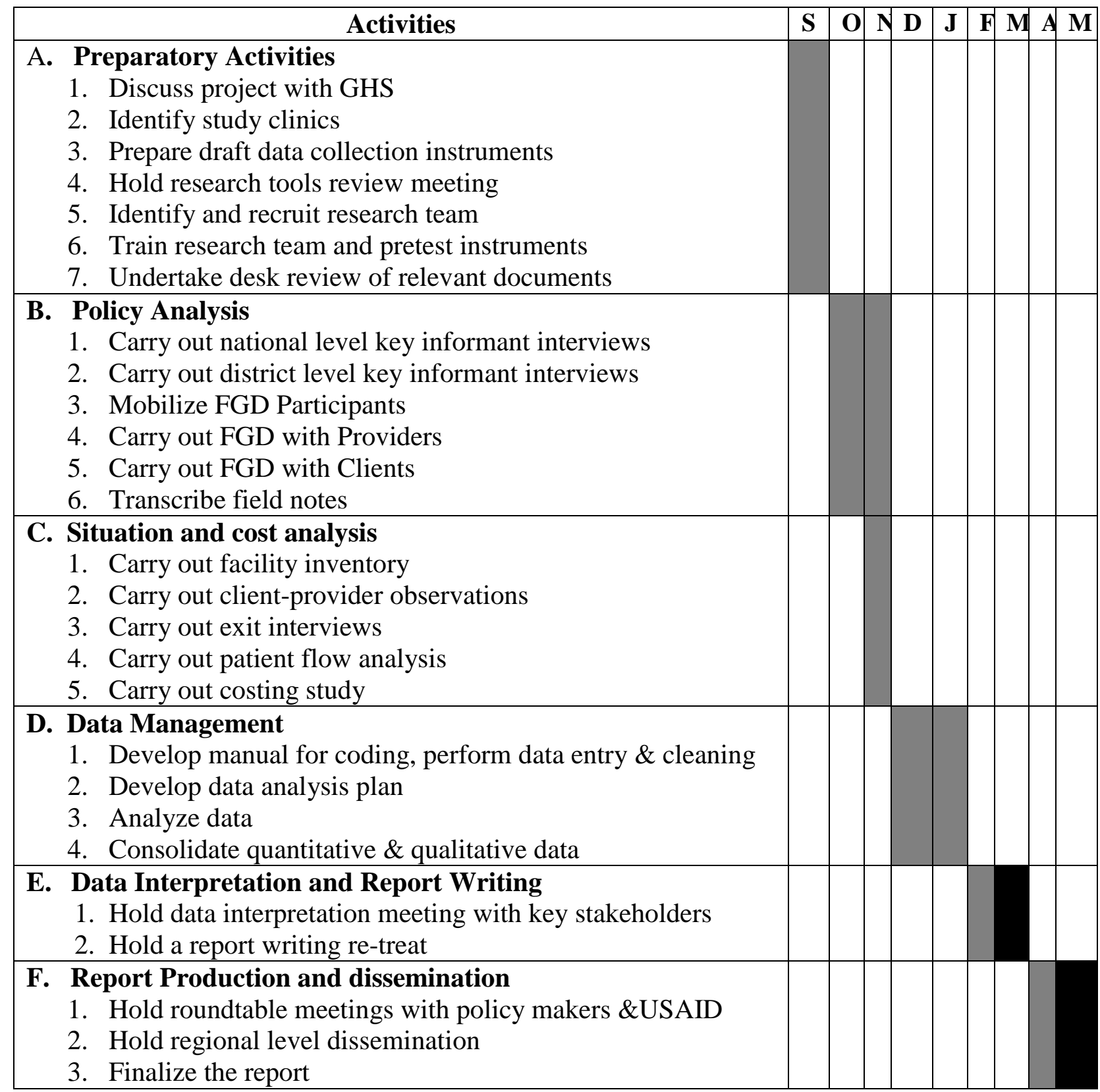


4. Disseminate report locally and regionally 


\section{Proposed Budget}

\begin{tabular}{|c|c|c|c|}
\hline Items & Unit cost & Cedi & US \$ \\
\hline $\begin{array}{l}\text { A. } \\
\text { 1. Personnel } \\
\text { 2. } \\
\text { 2. Co-incipal Investigator (Daniel - policy analysis) } \\
\text { 3. Co-investigator (Grace - situation analysis) } \\
\text { 4. } \quad \text { Data management time } \\
\end{array}$ & $\begin{array}{r}900,000 / \text { day } \times 8 \text { days/month } \times 9 \\
675,000 / \text { day } \times 8 \text { days/month } 99 \\
6,300,000 / \text { month } 95 \text { months } \\
13,500,000 / \text { month } \times 2 \text { months } \\
\end{array}$ & $\begin{array}{l}64,800,000 \\
48,600,000 \\
31,500,000 \\
27,000,000 \\
\end{array}$ & $\begin{array}{l}7,200 \\
5,400 \\
3,500 \\
3,000 \\
\end{array}$ \\
\hline $\begin{array}{ll}\text { B. } & \text { Policy analysis } \\
\text { 1. } & \text { Instrument development \& revision } \\
\text { 2. } & \text { Assistants' fees } \\
\text { 3. } & \text { Co-PI + Assistant (Meals + Incidentals) } \\
\text { 4. } & \text { Co-PI + Assistant (Accom) } \\
\text { 5. } & \text { FGD Mobilization \& refreshments } \\
\text { 6. } & \text { Transport (vehicle hire incl.fuel) } \\
\end{array}$ & $\begin{array}{r}3 \text { pp x } 135,000 / \text { day } \times 5 \text { days } \\
2 \text { months } \times 4,500,000 / \text { month } \\
2 \text { pp } \times 135,000 / \text { day } \times 60 \text { days } \\
2 \text { pp x } 350,000 / \text { day } \times 30 \text { days } \\
10 \text { groups } \times 1,350,000 / \text { group } \\
405,000 / \text { day } \times 60 \text { days } \\
\end{array}$ & $\begin{array}{r}2,025,000 \\
9,000,000 \\
16,200,000 \\
21,000,000 \\
13,500,000 \\
24,300,000 \\
\end{array}$ & $\begin{array}{r}225 \\
1,000 \\
1,800 \\
2,333 \\
1,500 \\
2,700\end{array}$ \\
\hline $\begin{array}{ll}\text { C. } & \text { Situation and cost analysis } \\
\text { 1. } & \text { Training (Meals + incidentals) } \\
\text { 2. } & \text { Training PI \& Co-PI (Meals + accom) } \\
\text { 3. } & \text { Data collection: Supervisor (fees) } \\
\text { 4. } & \text { Supervisor (meal + lodging) } \\
\text { 5. } & \text { Interviewers (fees) } \\
\text { 6. } & \text { Interviewers (meals) } \\
\text { 7. } & \text { Cost analysis (training +tools dept) } \\
\text { 8. } & \text { Cost analysis (data collection) } \\
\text { 9. } & \text { Monitoring, supervising } \\
& \text { Co- PI (meals + lodging) } \\
\text { 10. } & \text { Transport -Vehicle hire plus fuel } \\
\end{array}$ & 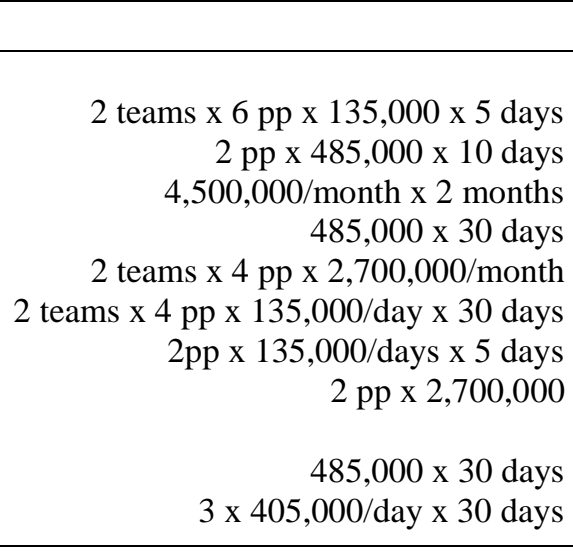 & $\begin{array}{r}8,100,000 \\
9,700,000 \\
9,000,000 \\
14,550,000 \\
21,600,000 \\
32,400,000 \\
1,350,000 \\
5,400,000\end{array}$ & $\begin{array}{r}900 \\
1,078 \\
1,000 \\
1,617 \\
2,400 \\
3,600 \\
150 \\
600\end{array}$ \\
\hline & & & 17,012 \\
\hline $\begin{array}{l}\text { D. Other direct costs } \\
\text { 1. Laptop computer } \\
\text { 2. General consumables } \\
\text { 3. Communication } \\
\text { 4. } \\
\end{array}$ & $\begin{array}{r}1 \times 22,500,000 \\
1,800,000 / \text { month } \times 9 \text { months } \\
1,350,000 / \text { month } \times 9 \text { months } \\
900,000 / \text { month } \times 9 \text { months } \\
\end{array}$ & $\begin{array}{r}22,500,000 \\
16,200,000 \\
12,150,000 \\
8,100,000 \\
\end{array}$ & $\begin{array}{r}2,500 \\
1,800 \\
1,350 \\
900 \\
\end{array}$ \\
\hline $\begin{array}{ll}\text { E. } & \text { Dissemination } \\
\text { 1. } & \text { Report writing - re-treats } \\
\text { 2. } & \text { In-country dissemination } \\
\text { 3. } & \text { Printing final report } \\
\end{array}$ & $\begin{array}{r}2 \text { meetings x } 11,250,000 / \text { meeting } \\
18,000,000\end{array}$ & $\begin{array}{r}9,000,000 \\
22,500,000 \\
18,000,000 \\
\end{array}$ & $\begin{array}{l}1,000 \\
2,500 \\
2,000 \\
\end{array}$ \\
\hline Project implementation budget & & & $\begin{array}{r}5,500 \\
57,720\end{array}$ \\
\hline NMIMR Overhead Costs & $15 \%$ of project impl. Budget & & 8,658 \\
\hline Overall budget to NMIMR & & & 66,378 \\
\hline
\end{tabular}




\section{Session 18: Instructor's Guide Course Wrap-Up/Questions and Answers}

\section{SESSION OBJECTIVES:}

- To review basic definitions and concepts

- To answer participants' questions about specific concepts, sessions or exercises

\section{POINTS TO EMPHASIZE:}

- The facilitators may not have adequately explained all material and the session is an opportunity to improve understanding of workshop contents

- Review the definition of OR, the pre-test post-test control group design with random assignment, and the characteristics of an OR problem

\section{SESSION METHOD:}

- Discussion

EXERCISES:

DURATION: 1 hour 